\title{
CYP24 inhibition as a therapeutic target in FGF23- mediated renal phosphate wasting disorders
}

\author{
Xiuying Bai, ${ }^{1}$ Dengshun Miao, ${ }^{2}$ Sophia Xiao, ${ }^{1}$ Dinghong Qiu, ${ }^{1}$ René St-Arnaud, ${ }^{3}$ Martin Petkovich,, ${ }^{4}$ Ajay Gupta, ${ }^{5}$ David Goltzman, ${ }^{6}$ \\ and Andrew C. Karaplis' \\ 'Lady Davis Institute for Medical Research, Division of Endocrinology, Jewish Ceneral Hospital, McGill University, Montreal, Quebec, Canada. ${ }^{2}$ The State Key Laboratory of Reproductive Medicine, The \\ Research Center for Bone and Stem Cells, Department of Anatomy, Histology and Embryology, Nanjing Medical University, Nanjing, China. ${ }^{3}$ Cenetics Unit, Shriners Hospital for Children, Montreal, Quebec, \\ Canada. ${ }^{4}$ Cancer Research Institute, Division of Cancer Biology and Genetics, Queen's University, Kingston, Ontario, Canada. OPKO Health Inc., Renal Division, Markham, Ontario, Canada. ${ }^{5}$ Department of \\ Oncology, Faculty of Medicine, McGill University, Montreal, Quebec, Canada. 'alcium Laboratory, Royal Victoria Hospital, McGill University Health Centre, Montreal, Quebec, Canada.
}

CYP24A1 (hereafter referred to as CYP24) enzymatic activity is pivotal in the inactivation of vitamin D metabolites. Basal renal and extrarenal CYP24 is usually low but is highly induced by its substrate 1,25-dihydroxyvitamin D. Unbalanced high and/ or long-lasting CYP24 expression has been proposed to underlie diseases like chronic kidney disease, cancers, and psoriasis that otherwise should favorably respond to supplemental vitamin D. Using genetically modified mice, we have shown that renal phosphate wasting hypophosphatemic states arising from high levels of fibroblast growth factor 23 (FCF23) are also associated with increased renal Cyp24 expression, suggesting that elevated CYP24 activity is pivotal to the pathophysiology of these disorders. We therefore crossed 2 mouse strains, each with distinct etiology for high levels of circulating FGF23, onto a Cyp24-null background. Specifically, we evaluated Cyp24 deficiency in Hyp mice, the murine homolog of X-linked dominant hypophosphatemic rickets, and transgenic mice that overexpress a mutant FGF23 (FGF23 ${ }^{\mathrm{R} 1760}$ ) that is associated with the autosomal dominant form of hypophosphatemic rickets. Loss of Cyp24 in these murine models of human disease resulted in near-complete recovery of rachitic/osteomalacic bony abnormalities in the absence of any improvement in the serum biochemical profile. Moreover, treatment of Hyp and FGF23 ${ }^{1760}$-transgenic mice with the CYP24 inhibitor CTA102 also ameliorated their rachitic bones. Our results link CYP24 activity to the pathophysiology of FCF23-dependent renal phosphate wasting states and implicate pharmacologic CYP24 inhibition as a therapeutic adjunct for their treatment.

\section{Introduction}

Fibroblast growth factor 23 (FGF23) is a bone-derived humoral factor underlying the etiology of several inherited and acquired renal phosphate wasting diseases $(1,2)$. It is highly expressed in osteocytes (3), and following secretion, it reaches the kidney to stimulate urinary phosphate excretion by inducing endocytosis of the sodium-phosphate cotransporters NPT2a and NPT2c from the apical membrane of renal proximal tubule cells (4). In addition, FGF23 impairs the production of renal 1,25dihydroxyvitamin $\mathrm{D}\left[1,25(\mathrm{OH})_{2} \mathrm{D}\right]$ by inhibiting the expression of CYP27B1, the enzyme that converts $25-(\mathrm{OH}) \mathrm{D}$ to its active metabolite, $1,25(\mathrm{OH})_{2} \mathrm{D}(5)$. FGF23 also upregulates the expression of vitamin D 24-hydroxylase (Cyp24a1, herein referred to as Cyp24) (5), a mitochondrial enzyme responsible for inactivating vitamin $\mathrm{D}$ metabolites through the $\mathrm{C}-24$ oxidation pathway. In the parathyroid, FGF23 directly inhibits the synthesis and secretion of parathyroid hormone (PTH) (6), perhaps utilizing it as a secondary mechanism for inhibiting $1,25(\mathrm{OH})_{2} \mathrm{D}$ synthesis. Therefore, FGF23 actions on the kidney and parathyroid glands appear to serve the primary purpose of maintaining phosphorus

Conflict of interest: M. Petkovich is Chief Scientific Officer of the Renal Division of OPKO Health Inc.

Submitted: March 17, 2015; Accepted: November 25, 2015.

Reference information: J Clin Invest. 2016;126(2):667-680. doi:10.1172/JCI81928. homeostasis by enhancing urinary phosphate excretion, while decreasing intestinal phosphorus absorption through lower circulating serum concentrations of $1,25(\mathrm{OH})_{2} \mathrm{D}$.

In a transgenic mouse model overexpressing the mutant form of FGF23, FGF23 ${ }^{\mathrm{R} 176 \mathrm{Q}}$, which is associated with the autosomal dominant form of hypophosphatemic rickets $(A D H R)$, we have reported high expression levels of Cyp24 in the kidneys (5, 7). Similar observations have been made in $H y p$ mice $(8,9)$, the murine homolog of X-linked hypophosphatemic rickets $(X L H)$, in which, in both humans and mice, inactivating mutations of phosphate-regulating endopeptidase homolog, X-linked (PHEX) also give rise to FGF23-dependent hypophosphatemia $(10,11)$. Hence, it was proposed that the paradoxical observation of low or inappropriately normal circulating $1,25(\mathrm{OH})_{2} \mathrm{D}$ levels observed in these disorders, despite the prevailing hypophosphatemia, arise from the decrease in its synthesis, along with the increase in its catabolism. This is unique to high FGF23-associated states, as in other renal phosphate wasting conditions, $1,25(\mathrm{OH})_{2} \mathrm{D}$ synthesis is appropriately increased by hypophosphatemia $(12,13)$.

We hypothesized, therefore, that increased CYP24 expression is a major contributor to the pathogenesis of renal phosphate wasting disorders due to excess FGF23 levels. Here, we have tested this supposition by crossing mice homozygous for the null Cyp24 allele with $H y p$ mice or with mice expressing the FGF $23^{R 176 Q}$ transgene, thereby obtaining in each case progeny 
with high circulating levels of FGF23 but lacking CYP24 enzymatic activity. We show that in the absence of CYP24, serum levels of phosphorus and $1,25(\mathrm{OH})_{2} \mathrm{D}$ did not improve, but the rachitic/osteomalacic bone abnormalities were ameliorated in these 2 animal models with high levels of FGF23 activity in the circulation. We have observed similar skeletal improvements using pharmacologic inhibition of CYP24 activity in Hyp and

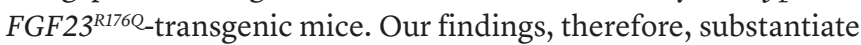
the concept that excess Cyp24 expression accompanying excess FGF23 activity lends itself to pharmacologic inhibition and could serve as a novel adjuvant therapeutic avenue for the treatment of FGF23-mediated renal phosphate wasting disorders.

\section{Results}

Analysis of Cyp24 $4^{-/}$Hyp Y mice. We first determined whether silencing of CYP24 enzymatic activity would alter any of the biochemical and/or skeletal manifestations arising from increased FGF23 expression. To address this question, we undertook a murine genetic approach and crossed Hyp mice with a strain homozygous for the null allele at the Cyp24 locus (14) to obtain Cyp24 $4^{--}$Hyp Y progeny (Figure 1A). Normally, only half of the Cyp24-null mice survive perinatally from the prevailing hypercalcemia and exhibit adaptive serum biochemical changes that serve to normalize serum calcium and phosphate levels. For the Hyp mice, we focused on males because of the likelihood of having more consistently severe disease due to the presence of only one $\mathrm{X}$ chromosome and, therefore, no WT allele for Phex. In contrast, heterozygous females have 1 normal and 1 abnormal Phex allele. Interestingly, the phenotypic features of these mice more closely approximated those of WT and Cyp24-/- animals (larger size, longer limbs and tail) than those of Hyp mice. Plain radiographs of long bones confirmed the apparent increase in long bone length and, in addition, the dramatic amelioration of the rachitic features such as widening of the growth plate and epiphyseal splaying that are characteristic of the Hyp phenotype (Figure 1B).

Cyp24 $4^{-/}$Hyp Y skeletal phenotype. We next examined in detail the skeletal changes arising in $H y p$ mice in the absence of CYP24 enzymatic activity. Micro-CT $(\mu \mathrm{CT})$ analysis of long bones (Figure 1C) as well as histological and histomorphometric assessment (Figure 1, D-F) confirmed the pronounced decrease in unmineralized growth plate thickness and bone osteoid in Hyp mice following Cyp24 deletion. Taken together, these findings added credence to our supposition that CYP24 activity is central to the rachitic and osteomalacic skeletal alterations associated with excess FGF23-mediated activity.

Serum biochemistry and renal Cyp27b1 expression in Cyp24-1Hyp Y mice. The question then arose as to whether there were concomitant improvements in Hyp serum levels of phosphorus, $1,25(\mathrm{OH})_{2} \mathrm{D}$, and FGF23 in the absence of $C y p 24$ that could account for the observed skeletal amelioration. However, we did not detect any such changes in serum biochemistry (Figure 2, A-F). In fact, serum levels of phosphorus, alkaline phosphatase (ALP) activity, and intact FGF23 paralleled those in Hyp mice, with the latter two increasing further following Cyp24 ablation. In contrast, circulating PTH levels became markedly suppressed and were accompanied by a further reduction in serum $1,25(\mathrm{OH})_{2} \mathrm{D}$ concentrations, while calcium levels remained unaltered. The lower
PTH concentration may have contributed in part to the further decrease in $1,25(\mathrm{OH})_{2} \mathrm{D}$ levels, as PTH normally serves to stimulate renal $C y p 27 b 1$ expression, which is elevated in kidneys from Hyp Y mice but nearly absent in kidneys from Cyp24-/- Hyp Y mice (Figure 2, G and H). The paradox of increased Cyp27b1 expression in the context of decreased enzymatic activity in FGF23mediated renal phosphate wasting disorders has been attributed to a defect in translational or posttranslational modification and not to aberrant transcriptional regulation (15). In summary, the lack of change in serum levels of calcium and, more specifically, phosphorus point to the involvement of other factors required to explain the profound skeletal amelioration in $H y p$ mice that arose following Cyp24 ablation.

Cyp24 deletion in FGF23 ${ }^{\text {R176Q }}$-transgenic mice. Increased FGF23 levels in Hyp mice arise due to loss of PHEX activity. We therefore questioned whether the skeletal improvements observed following Cyp24 deletion in this mouse model were indeed related to changes in actions arising from FGF23 overactivity and not due to those arising from loss of PHEX action. We sought to address this question by introducing the Cyp24-null allele in a mouse model of ectopic FGF23 overexpression, but where PHEX activity is preserved. Therefore, Cyp24-null mice were crossed with mice overexpressing human FGF23 $3^{\mathrm{R} 176 \mathrm{Q}}$ under the control of the human apolipoprotein E3 (APOE3) promoter. These transgenic animals $\left(F^{T g}\right)$ express a mutant form of FGF23 described in patients with autosomal dominant hypophosphatemic rickets $(A D H R)(14)$, which is resistant to proteolytic cleavage by furin proteases. This form of FGF23 has a longer circulating half-life and enhanced in vivo biological potency $(16,17)$, but PHEX activity remains normal. Moreover, ectopic expression of FGF23 ${ }^{\mathrm{R} 176 \mathrm{Q}}$ in mice gives rise to all the biochemical and rachitic and osteomalacic alterations observed as a consequence of FGF23 overactivity (7).

Following introduction of the Cyp24-null allele on an $F^{T g}$ background, progeny $\left(C y p 24^{-/} F^{T g}\right)$ were obtained that once again recapitulated the physical and biochemical alterations that characterized the Cyp24-/- Hyp Y mice. As shown in Figure 3, A and B, these mice displayed a profound amelioration of the bony rachitic and osteomalacic changes associated with FGF23 overexpression, as determined by radiographic and $\mu \mathrm{CT}$ analysis. Histologic assessment of long bones confirmed the amelioration in growth plate development and calcification and bone mineralization (Figure 3, $\mathrm{C}$ and $\mathrm{D})$. Moreover, the serum biochemical profile paralleled that of the Cyp24 $4^{--}$Hyp Y mice (Figure 4, A-F); that is, serum phosphorus and its renal handling as well as calcium levels did not change, while circulating PTH levels decreased and $1,25(\mathrm{OH})_{2} \mathrm{D}$ was reduced further, while transgenic FGF23 levels remained elevated following Cyp24 ablation (Figure 4G). In contrast to what was observed in Cyp24-/ Hyp Y mice, endogenous FGF23 levels did not change, as indicated by the suppressed carboxyl terminal fragment of FGF23 in the serum (Figure 4H). As anticipated, serum osteocalcin levels rose in $C y p 24^{-/-} F^{T g}$ mice compared with levels detected in $F^{T g}$ mice, consistent with increased bone formation and mineralization (Figure 4I). Moreover, renal Cyp27b1 expression was profoundly decreased in kidneys from $C y p 24^{-/-} F^{T g}$ mice (Figure 4, J-L). Our findings, therefore, would suggest that loss of CYP24 activity affects FGF23 actions, irrespective of whether FGF23 levels increase as a consequence of loss of PHEX activity or 

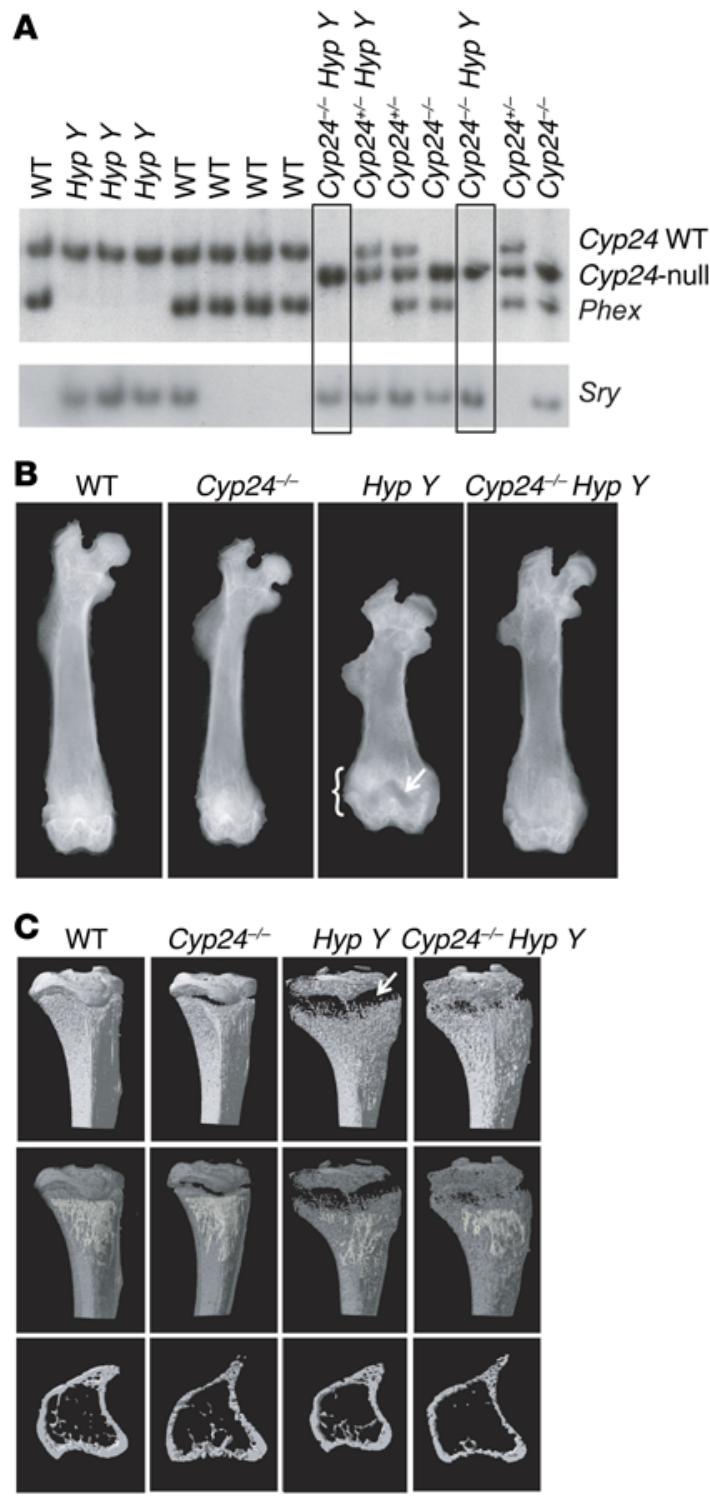
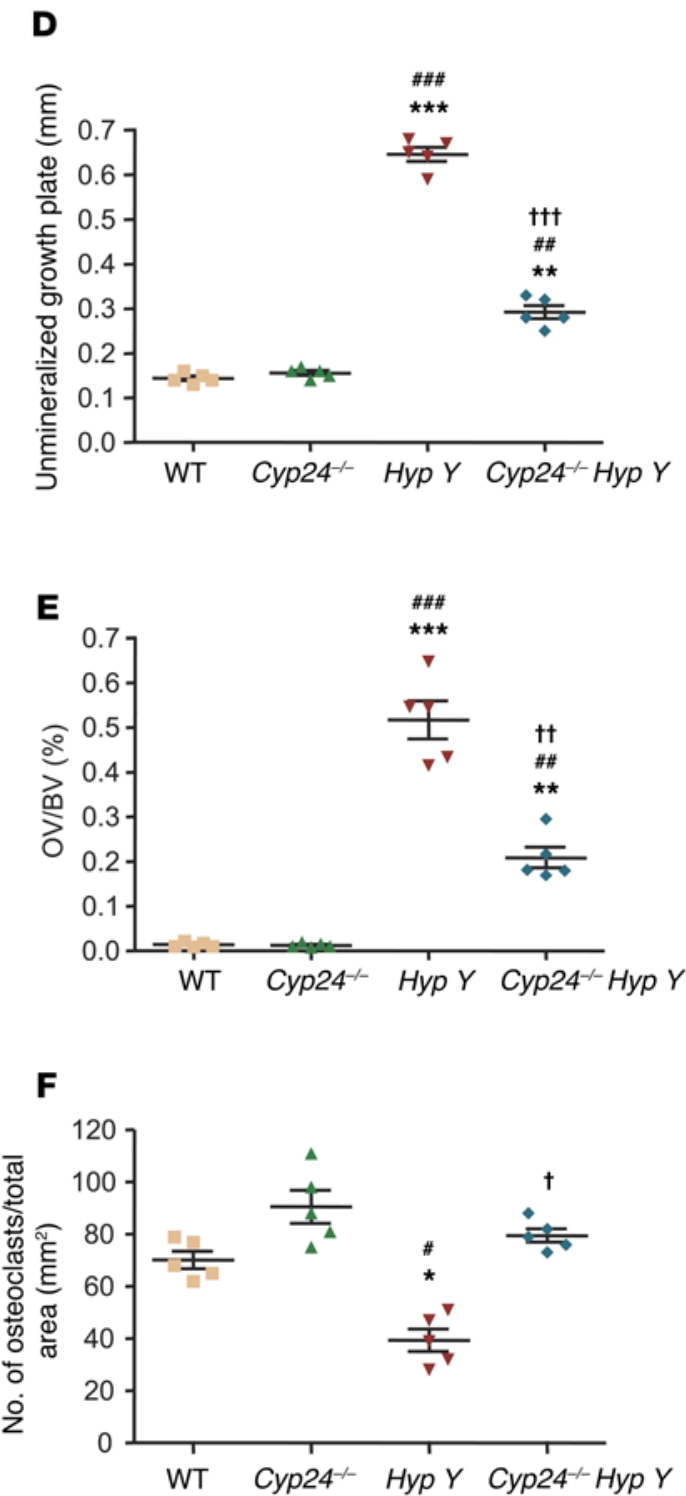

Figure 1. Generation of Cyp24-/- Hyp Y mice and bone morphology. (A). Southern blot analysis of tail genomic DNA. The presence of Sry and the absence of Phex were used to identify male mice of the Hyp genotype. (B) Representative contact radiographs of femurs from mice of the 4 indicated genotypes illustrating the increase in bone length observed in Hyp mice following Cyp24 ablation. Arrow shows widening of the growth plate; bracket shows splaying of the epiphysis. (C) $\mu \mathrm{CT}$ of long bones. Top panel: 3D reconstructed front views of the proximal ends of tibiae (arrow illustrates widening and lack of mineralization of the Hyp growth plate); middle panel: longitudinal; bottom panel: cross-sectional views of tibiae obtained from $\mu$ CT scan images of 52-day-old mice of the indicated genotypes. Quantitative analyses of (D) unmineralized thickness of growth plates, (E) percentage of osteoid volume (OV) per bone volume (BV), and $(\mathbf{F})$ number of osteoclasts per total area, as measured by computer-assisted image analysis. Each value represents the mean \pm SEM of determinations in 5 mice of each genotype. ${ }^{*} P<0.05,{ }^{* *} P<0.01$, and ${ }^{* * *} P<0.001$ compared with WT mice; ${ }^{\#} P<0.05$, \#\# $P<0.01$, and ${ }^{\# \# \# ~} P<0.001$ compared with Cyp24 ${ }^{-1-}$ mice; and ${ }^{\dagger} P<0.5,{ }^{\dagger+} P<0.01$, and ${ }^{t+\dagger} P<0.001$ compared with Hyp $Y$ mice, all determined by 1-way ANOVA with Tukey's multiple comparisons post test.

from direct ectopic expression, as observed in the $F^{T g}$ mice. Given these additional observations, we can conclude that loss of CYP24 activity leads to a dramatic amelioration of the bone phenotype associated with FGF23-mediated renal phosphate wasting disorders, without impacting serum calcium or phosphorus concentrations and despite further decreasing levels of serum $1,25(\mathrm{OH})_{2} \mathrm{D}$.

Increased renal and intestinal calcium transport. We then questioned why the decreases in circulating PTH and $1,25(\mathrm{OH})_{2}$ D serum levels failed to have a negative impact on serum calcium concentrations. Increased calcium reabsorption at the level of the kidney by FGF23 through the transient receptor potential cation channel, subfamily V, member 5 (TRPV5) channel (18) may have accounted in part for the maintenance of serum calcium levels. Indeed, Trpv5 levels were increased in kidneys from Cyp24- ${ }^{T^{T_{S}}}$ mice compared with levels in transgenic mice (Figure 5A). In addition, augmented expression of other key regulators of calcium renal handling was observed, such as for Trpv6, calbindin-D28K (Calb1), and calbindin-D9k $(S 100 g)$ (Figure 5, B-D). Similar changes were observed in other active vitamin D-responsive tissues, specifically the duodenum, where expression of Trpv6 and $5100 \mathrm{~g}$ was significantly potentiated (Figure 5, E and F). These findings provide an explanation for the capacity of Cyp $24^{-/} F^{T_{g}}$ and probably Hyp Y Cyp $24^{-/-}$ 

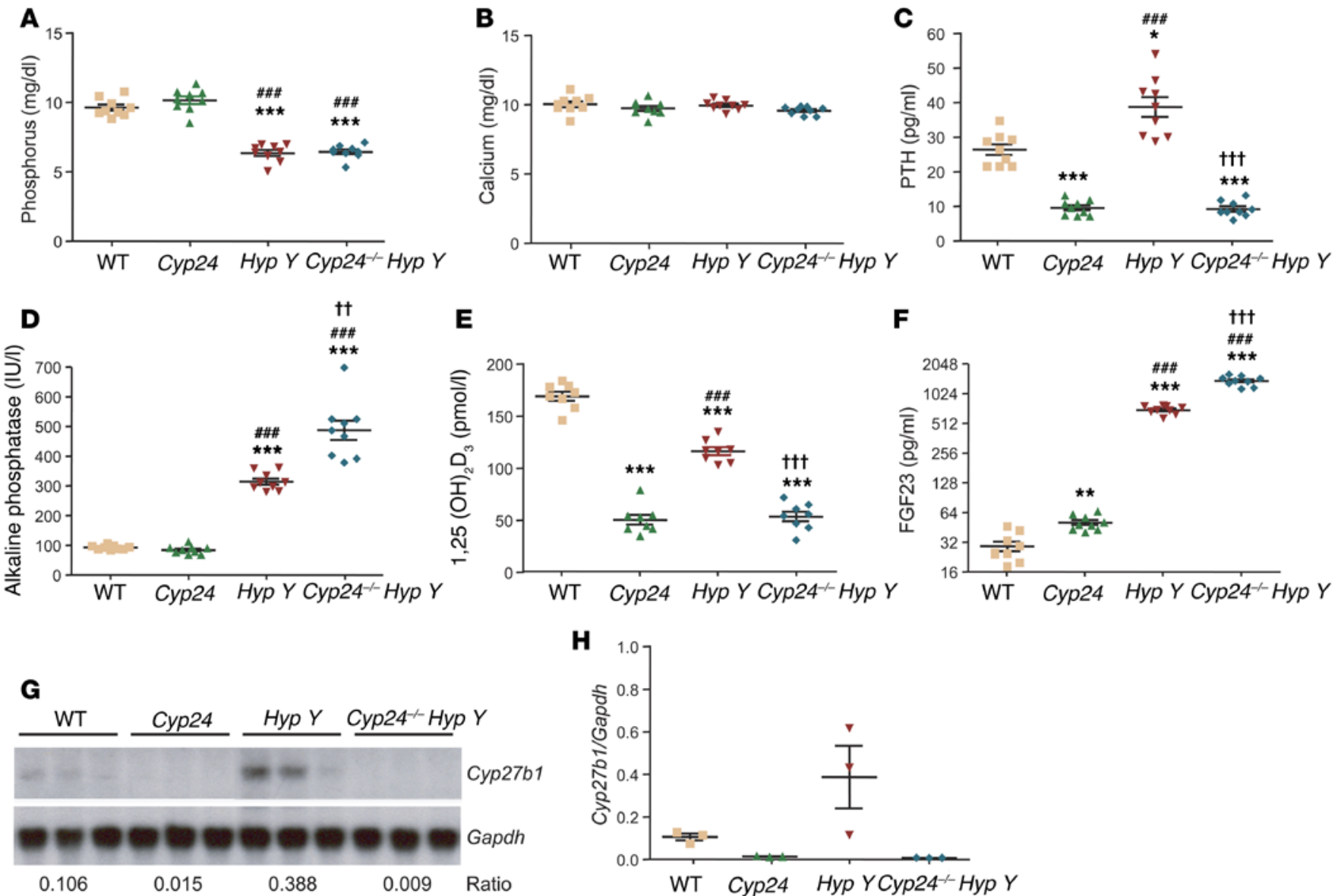

Figure 2. Serum biochemistry and renal Cyp27b1 expression in Cyp24-- Hyp Y mice. Serum levels of (A) phosphorus, (B) calcium, (C) PTH, (D) ALP activity, (E) 1,25-dihydroxyvitamin $D_{3}\left[1,25(\mathrm{OH})_{2} D_{3}\right]$, and (F) intact FGF23 in mice of the indicated genotypes. Results represent the mean \pm SEM $(n=8-9$ mice/

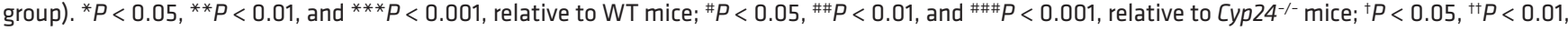
and ${ }^{t+t} P<0.001$, relative to Hyp $Y$ mice, all determined by 1-way ANOVA with Tukey's multiple comparisons post test. (G) Northern blot analysis of renal Cyp27b1 expression in kidneys from WT, Cyp24 $4^{--}$, Hyp Y, and Cyp24 ${ }^{-/-}$Hyp Y mice. Gapdh expression was used as a loading control. (H) Graphic representation of Cyp27b1/Gapdh expression ratio in kidneys from the indicated genotypes.

mice to maintain serum calcium concentrations in the presence of decreasing circulating levels of PTH and $1,25(\mathrm{OH})_{2} \mathrm{D}$. In addition, these findings implicate factors other than FGF23 being responsible for the observed increase in calcium handling.

Increased tissue levels of $1,25(\mathrm{OH})_{2} D$ in $\mathrm{Cyp}_{2} 4^{-/} F^{\mathrm{Tg}}$ mice. $1,25(\mathrm{OH})_{2} \mathrm{D}$ acts as one of the key regulators of calcium handling in kidney and duodenum by acting on the vitamin D response element and altering expression of the main calcium transport proteins TRPV5, TRPV6, CALB1, and S100G (19-22). Since circulating levels of active vitamin D were decreased in $C y p 24^{-/-} F^{T g}$ mice, a plausible explanation stems from the likelihood that it is the tissue levels of $1,25(\mathrm{OH})_{2} \mathrm{D}$ that increase due to local production by CYP27B1 in association with a completely ineffective catabolic pathway, in other words, a total absence of CYP24 activity. Cyp24 expression is not unique to the proximal renal tubule epithelium but has been observed in many other tissues including the parathyroid glands, chondrocytes, and enterocytes $(23,24)$. Therefore, rising tissue levels of $1,25(\mathrm{OH})_{2} \mathrm{D}$ in renal and intestinal epithelial cells would increase calcium transport, while in the parathyroid cells, it would cause the observed decrease in PTH secretion. On the other hand, in the developing bone, it would lead to improved mineralization of the growth plate and amelioration of the rachitic and osteomalacic changes observed.

To confirm this supposition, we examined tissue $1,25(\mathrm{OH})_{2} \mathrm{D}$ levels in kidney and confirmed the anticipated increase in Cyp24 $4^{-/} F^{T g}$ mice compared with levels detected in $F^{T g}$ mice (Figure $5 \mathrm{G}$ ). A similar trend was also evident in long bones, although the differences were not statistically significant (Figure $5 \mathrm{H}$ ). This rise in local $1,25(\mathrm{OH})_{2} \mathrm{D}$ levels occurs despite the evident decrease in its circulating concentration, thereby substantiating the increased local tissue production of the hormone in the absence of CYP24 enzymatic activity.

Pharmacologic inhibition of CYP24 activity in vivo. We then examined whether pharmacologic inhibition of CYP24 activity in vivo could be used to improve the associated rachitic and osteomalacic abnormalities that arise from increased FGF23 activity in Hyp $Y$ mice. To address this question, we administered either vehicle or a specific CYP24 inhibitor, CTA102 ( IC $_{50} 8.5 \mathrm{nM}$ ) (Figure 6, A-D), to $H y p$ Y mice i.p. daily for 8 weeks, starting at 4 weeks of age, and measured serum biochemical and bone parameters. 
A

B
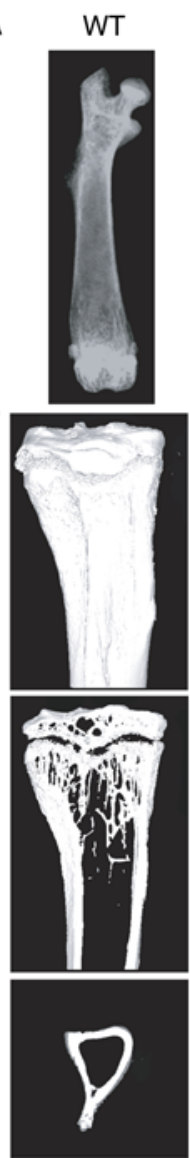

Cyp24-
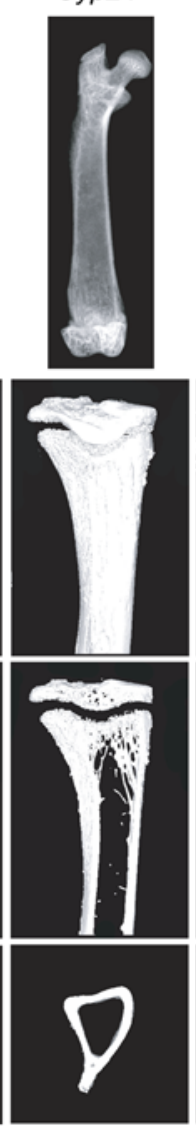

$F^{T g}$

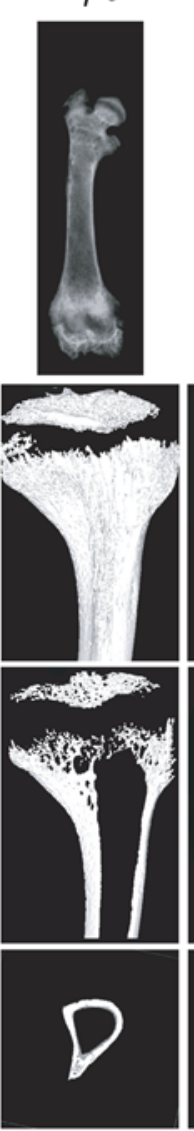

Cyp24 $4^{-\sim F^{T g}}$
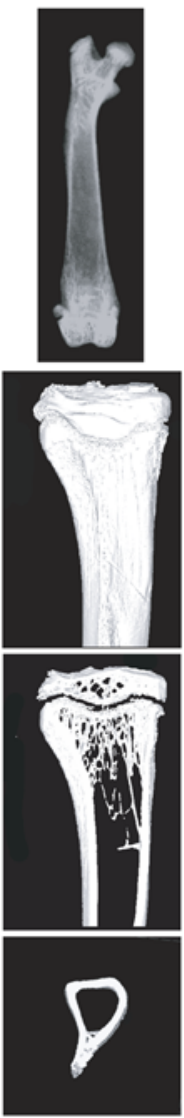

C

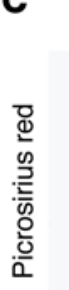

WT
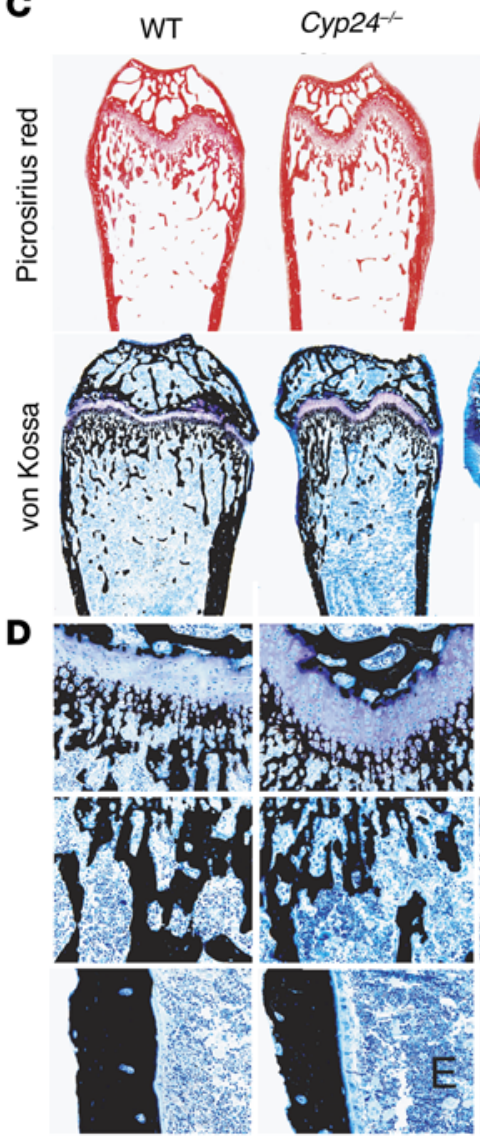

$F^{T_{g}}$

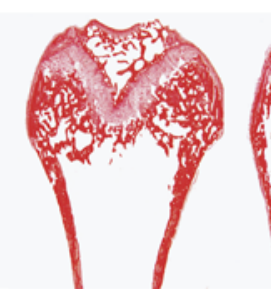

Cyp24- ${ }^{-1 g}$
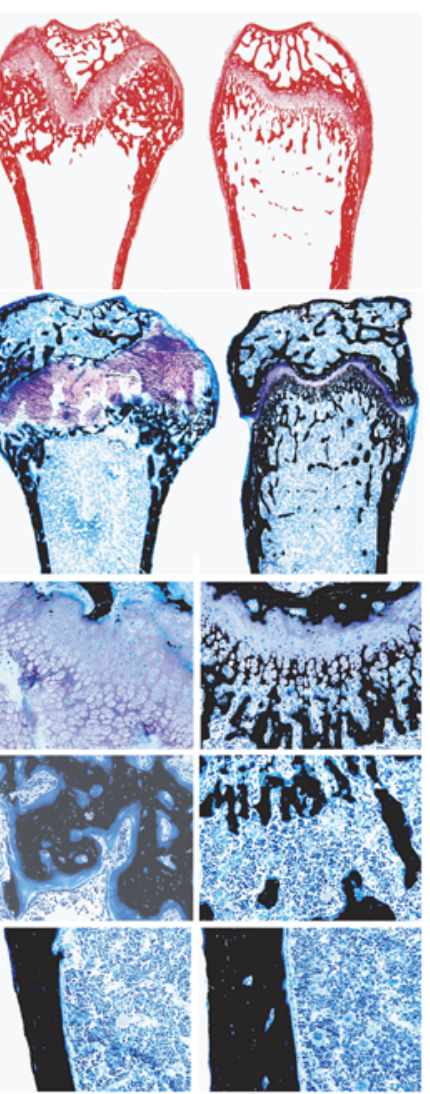

Figure 3. Bone morphology of Cyp24 ${ }^{-/-} \boldsymbol{F}^{T g}$ mice. (A) Representative contact radiographs of femurs. (B) $\mu$ CT of long bones. 3D reconstructed front views of the proximal end of tibiae (top panel), longitudinal sections (middle panel), and cross sections (lower panel) of tibiae from $\mu \mathrm{CT}$ scanned images of mice of the indicated genotypes. (c) Histologic analysis of long bones from 52-day-old mice of the indicated genotypes. Representative micrographs (original magnification, $\times 20$ ) of Picrosirius red- (for the histological visualization of collagen fibers) and von Kossa- (to visualize mineralization) stained sections from the distal ends of femurs from mice of each indicated genotype. (D) Higher magnification (original magnification, $\times 200$ ) of the growth plate (top), metaphysis (middle), and cortex (bottom).

Treatment with CTA102 did not alter body weight or serum levels of phosphorus, calcium, or PTH, but it significantly increased the levels of circulating $1,25(\mathrm{OH})_{2} \mathrm{D}$ (Figure 7, A-E). The latter is a true indicator of CYP24 inhibition and contrasts with the negative effects on vitamin D metabolism by the adaptive responses that had taken place in the Cyp24-null mice to prevent early lethality due to hypervitaminosis D. Moreover, there was a parallel rise in serum levels of FGF23 (Figure 7F). This could have occurred, in part, in response to the increase in serum $1,25(\mathrm{OH})_{2} \mathrm{D}$ levels. Nevertheless, while serum levels of 1,25(OH) ${ }_{2} \mathrm{D}$ in CTA102-treated Hyp Y mice were comparable to those in WT mice, FGF23 immunostaining was significantly more pronounced in the CTA102-treated growth plates (Figure $7, \mathrm{G}$ and $\mathrm{H})$, suggesting that local increases of $1,25(\mathrm{OH})_{2} \mathrm{D}$ in tissues are likely an additional contributor to the higher FGF23 expression levels. Examination of long bones from treated mice identified improvements in a number of $\mu \mathrm{CT}$-derived parameters including decreased growth plate thickness and bone osteoid, with parallel increases in bone volume and trabecular numbers with less separation, all of which are indicators of improved skeletal development and mineralization (Figure 8,
A-F). We made similar observations in FGF23 ${ }^{R 176 Q}$-transgenic mice treated with CTA102 (data not shown). Although the serum biochemical changes did not completely reflect those observed following complete Cyp24 deletion, they once again illustrated the beneficial consequences of CYP24 inhibition on the actions of $1,25(\mathrm{OH})_{2} \mathrm{D}$ and specifically on its osteoanabolic effects, despite higher circulating levels of FGF23 and persistent hypophosphatemia. These findings therefore add credence to our observation that inhibition of CYP24 enzymatic activity in Hyp mice positively impacts skeletal mineralization by improving the rachitic and osteomalacic bone abnormalities that arise as a consequence of increased activity of circulating FGF23.

\section{Discussion}

The findings described in this work highlight the pivotal role of CYP24 activity in the pathophysiology of FGF23-dependent renal phosphate wasting disorders and bring to the forefront the importance of the extrarenal expression of this enzyme in local tissue and total body physiology (Figure 9). CYP24 is expressed in a variety of tissues, including kidney, intestine, and bone, and is induced by $1,25(\mathrm{OH})_{2} \mathrm{D}$ itself, thus regulating its own break- 

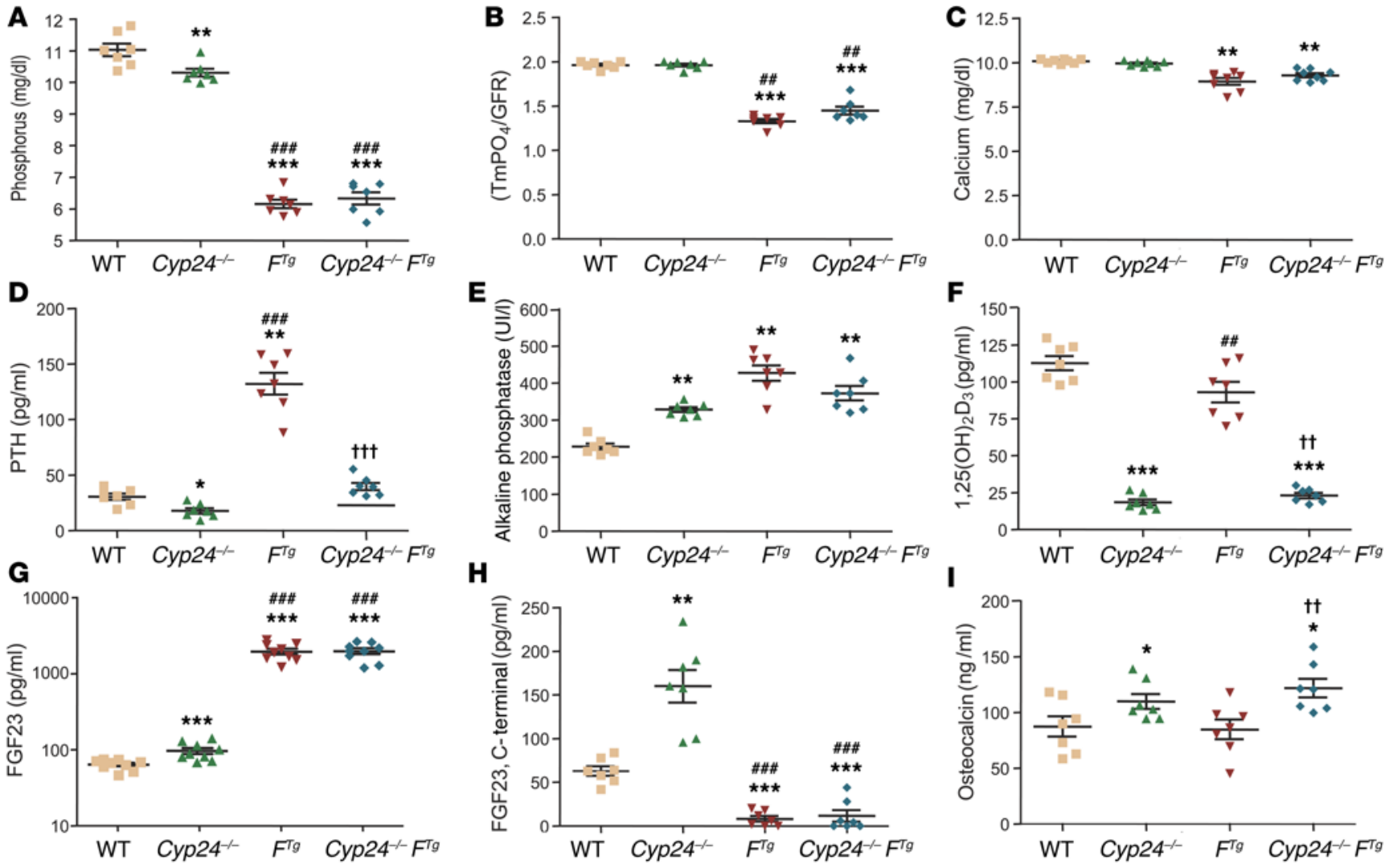

J

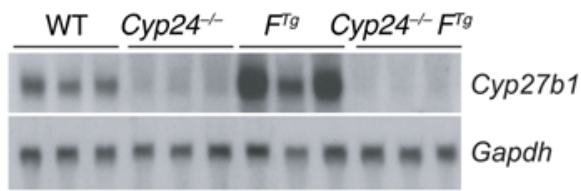

$\mathbf{K}$

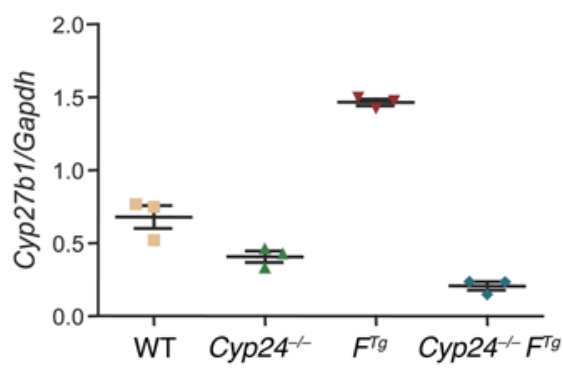

L
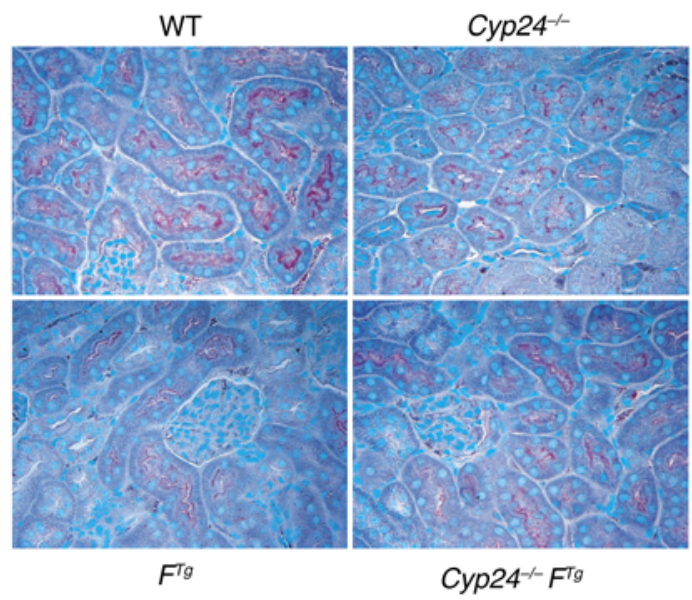

Figure 4. Serum biochemistry and CYP27B1 expression in Cyp24-/- $\boldsymbol{F}^{T_{g}}$ mice. Serum levels of (A) phosphorus, (B) renal threshold for phosphorus $\left(\mathrm{TmPO}_{4} / \mathrm{GFR}\right.$ ), (C) calcium, (D) PTH, (E) ALP activity, (F) 1,25(OH) 2 , (G) FGF23, (H) C-terminal fragment of FGF23, and (I) osteocalcin in mice of the indicated genotypes. GFR, glomerular filtration rate. Results are expressed as the mean \pm SEM $\left(n=7-9\right.$ mice/group). ${ }^{*} P<0.05$, ${ }^{* *} P<0.01$, and ${ }^{* * *} P<0.001$, relative to WT mice; ${ }^{*} P<0.05$, ${ }^{\# \#} P<0.01$, and ${ }^{\# \# \# ~} P<0.001$, relative to Cyp24 ${ }^{-1-}$ mice; ${ }^{\dagger} P<0.05,{ }^{+\dagger} P<0.01$, and ${ }^{t+t} P<0.001$, relative to Hyp Y mice, all determined by 1-way ANOVA with Tukey's multiple comparisons post test. (J) Northern blot analysis of renal CYP27B1 expression in kidneys from WT, Cyp24 $4^{-/-}, F^{T g}$, and Cyp24 ${ }^{-/-} F^{T_{g}}$ mice. Gapdh expression was used as a loading control. (K) Graphic representation of the Cyp27b1/ Gapdh expression ratio in kidneys from mice of the indicated genotypes. (L) CYP27B1 immunoreactivity in kidney from the indicated mouse genotypes (original magnification, $\times 400$ ).

down (25). Increased renal Cyp24 mRNA and immunoreactive protein has been proposed as one of the mechanisms for accelerated $1,25(\mathrm{OH})_{2} \mathrm{D}$ catabolism in $H y p X L H$ mice $(26,27)$. Moreover, CYP24 activity and plasma concentrations of $24,25(\mathrm{OH})_{2} \mathrm{D}$ were reported to be significantly higher in $H y p$ mice than in WT mice when both groups were fed a normal diet (28). Hence, in Hyp mice, CYP24 activity is reset, such that it is inappropriately high for the prevailing serum phosphorus level over a wide range of concentrations, leading to both increased catabolism of $1,25(\mathrm{OH})_{2} \mathrm{D}$ and decreased substrate availability for its formation. 
A

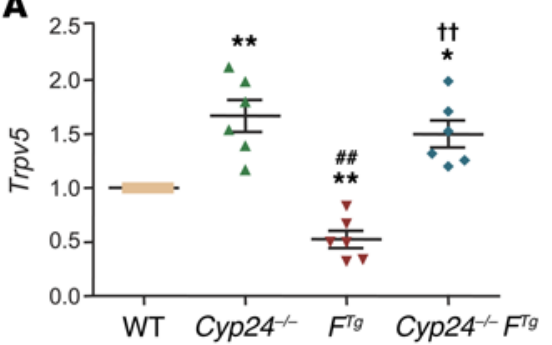

C

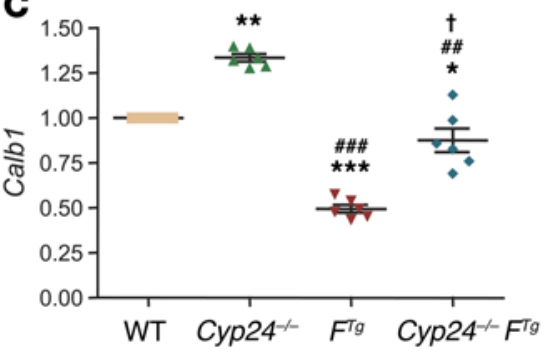

$\mathbf{E}$

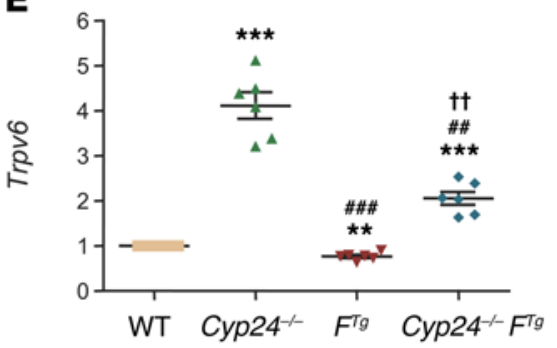

G

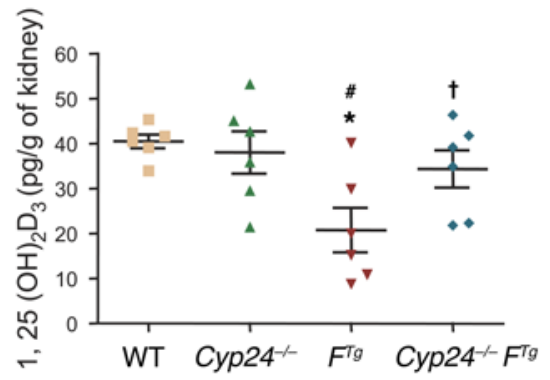

B

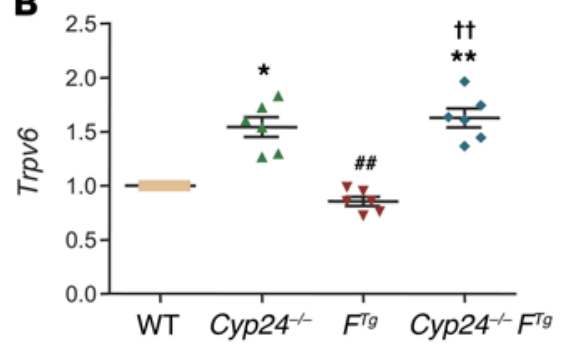

D

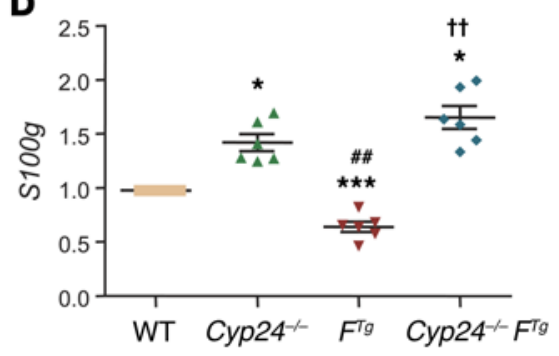

$\mathbf{F}$

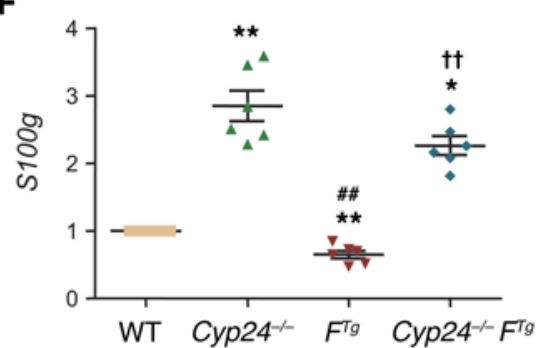

H

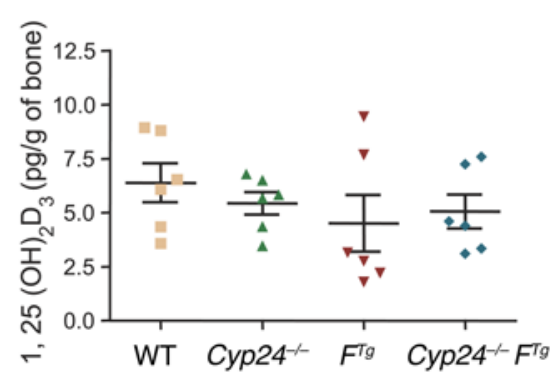

Figure 5. Altered expression of calcium transporters and 1,25(OH) $D$ levels in tissue from Cyp24-/- F ${ }^{T_{g}}$ mice. (A) Trpv5, (B) Trpv6, (C) Calb1 (calbindin D28K), and (D) $5100 \mathrm{~g}$ (calbindin D9K) expression in kidneys. Results are expressed as the mean \pm SEM ( $n=6$ mice/group). (E) Trpv6 and (F) $5100 \mathrm{~g}$ expression in the proximal intestinal tract (duodenum). Values are expressed as the ratio over actin expression, normalized to 1 for the WT samples. ${ }^{*} P<0.05$, ${ }^{* *} P<0.01$, and ${ }^{* *} P<0.001$, relative to WT mice; ${ }^{\#} P<0.05$, \#\# $P<0.01$, and ${ }^{\# \# P} P 0.001$, relative to Cyp24 $4^{-1-}$ mice; ${ }^{\dagger} P<0.05,{ }^{\dagger \dagger} P<0.01$, and ${ }^{+t \dagger} P<0.001$, relative to $F^{T g}$ mice. (G) $1,25(\mathrm{OH})_{2} \mathrm{D}_{3}$ levels in kidney and $(\mathbf{H})$ bone. Results are expressed as the mean \pm SEM ( $n=6$ mice/group). ${ }^{*} P<0.05$, relative to $\mathrm{WT}$ mice; ${ }^{~} P<0.05$, relative to Cyp24-/- mice; and ${ }^{\dagger} P<0.05$, relative to $F^{T g}$ mice. All statistics were calculated using 1-way ANOVA with Tukey's multiple comparisons post test

What, then, are the consequences of decreased $1,25(\mathrm{OH})_{2} \mathrm{D}$ function in the peripheral tissues of $H y p$ mice? Extrarenal synthesis of $1,25(\mathrm{OH})_{2} \mathrm{D}$ plays a key role in the regulation of cell growth and differentiation at various sites in the body. At the parathyroid level, for example, transcription of $P T H$ is repressed by $1,25(\mathrm{OH})_{2} \mathrm{D}$. The hormone binds to the vitamin $\mathrm{D}$ receptor (VDR), and the ligand-VDR complex, in association with the retinoic acid $\mathrm{X}$ receptor (RXR), binds to a vitamin D response element within the promoter region of the $P T H$ gene (27). Deletion of the VDR specifically in the parathyroid increases basal PTH levels, confirming that the vitamin D signaling plays a role in parathyroid physiology (31). Increased CYP24 expression in the Hyp parathyroid cell would reduce local concentrations of $1,25(\mathrm{OH})_{2} \mathrm{D}$ in the tissue and hence its repressive effect on Pth transcrip-

CYP24 is the major $1,25(\mathrm{OH})_{2} \mathrm{D}$-inactivating enzyme. It is considered the pivotal determinant of the biological half-life of $1,25(\mathrm{OH})_{2} \mathrm{D}$ and plays a key role in fine-tuning the levels and actions of $1,25(\mathrm{OH})_{2} \mathrm{D}$ at the tissue level. Intervention with vitamin D analogs often stimulates the expression of CYP24 (29, 30 ), resulting in rapid elimination of the active metabolites. This property drastically reduces the effectiveness of the treatment with $1,25(\mathrm{OH})_{2} \mathrm{D}$ and could be responsible for its controversial efficacy in the treatment of disorders such as chronic kidney disease, cancers, psoriasis, and perhaps now renal phosphate wasting disorders caused by excess FGF23 activity that would otherwise respond to endogenous or supplemental vitamin $\mathrm{D}$ in a favorable way. Therefore, the unbalanced high and/or long-lasting expression of CYP24 contributes to the pathology of these diseases by reducing the local availability of $1,25(\mathrm{OH})_{2} \mathrm{D}$ and hence its beneficial efficacy. tion. On the other hand, deleting or pharmacologically inhibiting CYP24 activity allows for locally produced $1,25(\mathrm{OH})_{2} \mathrm{D}$ to exert its repressive effects on gene transcription, leading to the observed decrease in serum PTH secretion, despite increased serum levels of FGF23 and lower renal CYP27B1 activity, with further attenuation of circulating $1,25(\mathrm{OH})_{2} \mathrm{D}$.

In vitro studies using cells of the osteogenic lineage have corroborated the expression of CYP27B1 and CYP24 in these cells as they metabolize $25(\mathrm{OH}) \mathrm{D}$ to $1,25(\mathrm{OH})_{2} \mathrm{D}$ and $24,25(\mathrm{OH})_{2} \mathrm{D}(32)$. Locally produced $1,25(\mathrm{OH})_{2} \mathrm{D}$ then promotes differentiation, in part by upregulation of p21Waf1/Cip1 and decreased expression of cyclin D1. Ultimately, these actions enhance bone mineral deposition (33-36). Moreover, enhanced vitamin D activity in mature osteoblasts achieved by increasing levels of VDR or CYP27B1 leads to improved bone mineral volume and mineralization $(37,38)$. Conversely, CYP24 overexpression in bone cells (39) would reduce the 
A
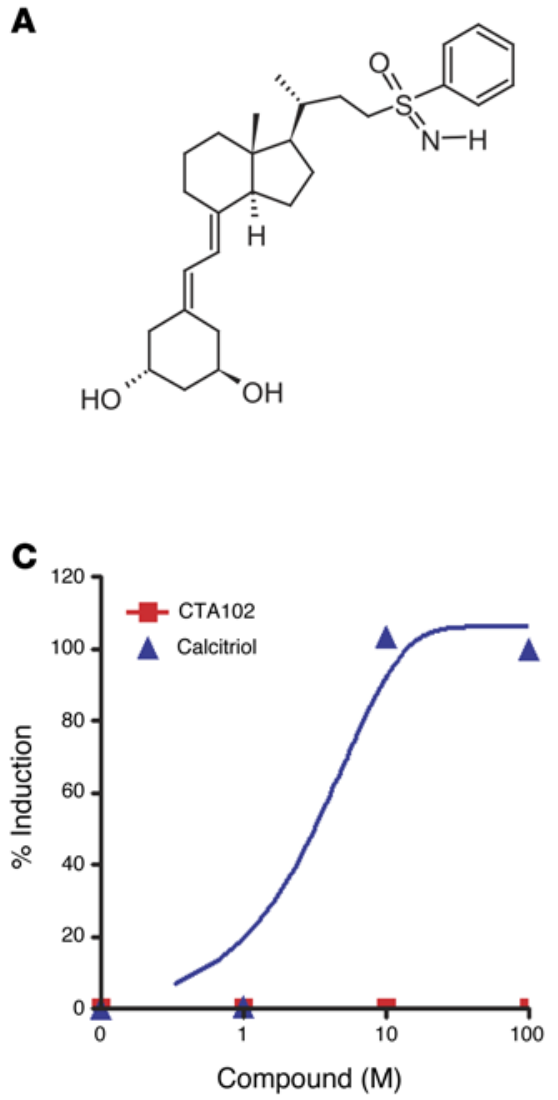

B

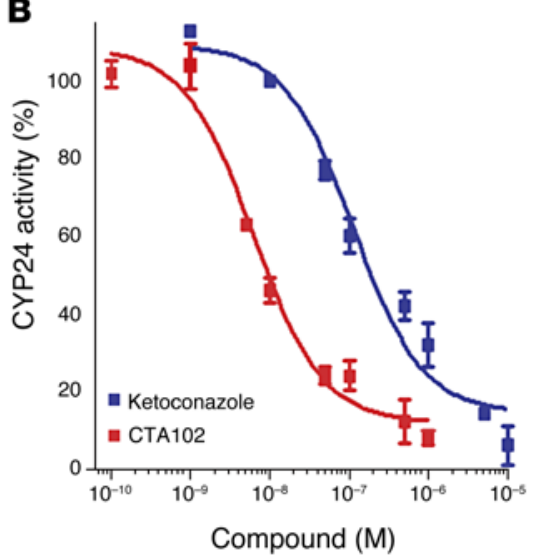

D

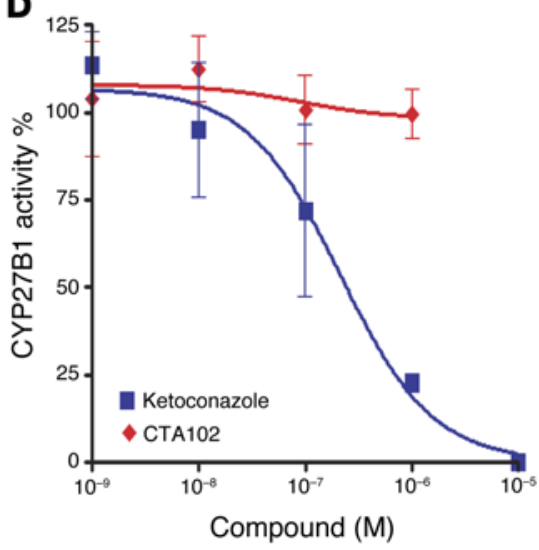

Figure 6. Biochemical properties of the CYP24 inhibitor CTA102. (A) Molecular structure of CTA102. (B) CYP24 inhibitory activity of CTA102 $\left(\mathrm{IC}_{50} 8.5 \mathrm{nM}\right)$ compared with that of ketoconazole. (C) Induction of CYP24 enzymatic activity by CTA102 compared with that induced by calcitriol. (D) CYP27B1 inhibitory activity of CTA102 $\left(\mathrm{IC}_{50}\right.$ $>1,000 \mathrm{nM}$ ) compared with that of ketoconazole.

graphs was partially corrected. Together, these findings provide strong evidence that the genesis of skeletal abnormalities in $H y p$ mice are not entirely mediated by serum phosphate concentrations (48).

It follows from this discussion that pharmacologic inhibition of CYP24 would have beneficial actions, and inhibition of CYP24 could be the appropriate strategy to increase the half-life and thereby the function of vitamin D in tissues. The present study therefore contributes to the currently emerging concept of intracrinology (49), whereby locally produced bioactive steroid hormones exert their action in the cells in which their synthesis occurs, without release into the extracellular space, including the circulation. This has been demonstrated in tissues such as keratinocytes (50), osteoblasts (33), and chondrocytes (43) and implicates a

local cellular concentration of $1,25(\mathrm{OH})_{2} \mathrm{D}$ and hence attenuate its osteoanabolic effects (40). Consequently, deletion or pharmacological inhibition of CYP24 activity in Hyp mice would allow locally synthesized $1,25(\mathrm{OH})_{2} \mathrm{D}$ to exert its beneficial effects on bone and the observed amelioration of the various bone parameters.

In addition to osteoblasts, growth plate chondrocytes also express VDR (41), CYP27B1, and CYP24 and respond to $1,25(\mathrm{OH})_{2} \mathrm{D}$ and $24,25(\mathrm{OH})_{2} \mathrm{D}(23)$. Therefore, local production of $1,25(\mathrm{OH})_{2} \mathrm{D}$ in an autocrine or paracrine fashion likely contributes to the differentiation of these cells. This would explain why bone growth remains impaired in Cyp27b1-null mice following correction of mineral homeostasis (42), an observation subsequently confirmed by chondrocyte-specific targeted deletion of Cyp27b1 (43). These results corroborate the phenotype observed in chondrocyte-specific VDR-ablated mice (44) and support an autocrine/ paracrine role for $1,25(\mathrm{OH})_{2} \mathrm{D}$ in chondrocyte development in vivo. It would be anticipated, therefore, that deletion or pharmacologic inhibition of CYP24 activity in Hyp mice would result in higher local concentrations of $1,25(\mathrm{OH})_{2} \mathrm{D}$ and the observed amelioration in growth plate development and calcification.

It was rather unanticipated to see such a dramatic amelioration in growth plate calcification and bone mineralization in the murine models studied, given the lack of improvement in circulating phosphate levels. Previous studies, however, substantiate our findings. For example, overexpression of PHEX under the control of bone-specific (osteocalcin or type I collagen) or $\beta$-actin promoters did not correct phosphate wasting (45-47), yet the mineralization defect in bones we observed in histological studies and radio- transition from a hormone acting at a distant site of synthesis to a local factor acting in an intracrine/autocrine manner. Furthermore, by inhibiting the inactivating enzyme, the amount of active vitamin $\mathrm{D}$ or its analogs required to elicit beneficial effects could be reduced in vivo, thereby preventing untoward side effects from their administration $(51,52)$. Hence, inhibition of CYP24 opens up a field of possible therapeutic applications for the prevention and treatment of FGF23-mediated renal phosphate wasting diseases.

The Hyp mouse has serum FGF23 concentrations 10-fold higher than those found in WT mice (53). Although there is wide variation, the majority of patients with $X L H$, the most common inherited form of rickets, also have elevated serum FGF23 concentrations (54). The inhibition of FGF23 production or activity, therefore, is theoretically an ideal treatment for these hypophosphatemic states. It is recognized, however, that, while the current therapeutic intervention for patients with $X L H$ involving highdose phosphate and calcitriol improves the osteomalacia (55), it remains less than ideal, as growth remains suboptimal in many patients (56) and complications such as diarrhea, nephrocalcinosis, hyperparathyroidism, and the imperfect restoration of bone due to persistence of undermineralization prevail (57). In fact, it has been stated that, at times, the treatment may be worse than the disease (58). Therefore, newer therapeutic approaches such as inhibitors of the FGF receptor (59) and of extracellular signal-regulated kinase (60) as well as anti-FGF23 Abs (61) remain under active investigation.

Although it could be argued that a local increase of $1,25(\mathrm{OH})_{2} \mathrm{D}$ in the osteocyte by CYP24 inhibitors may in fact be detrimental by 

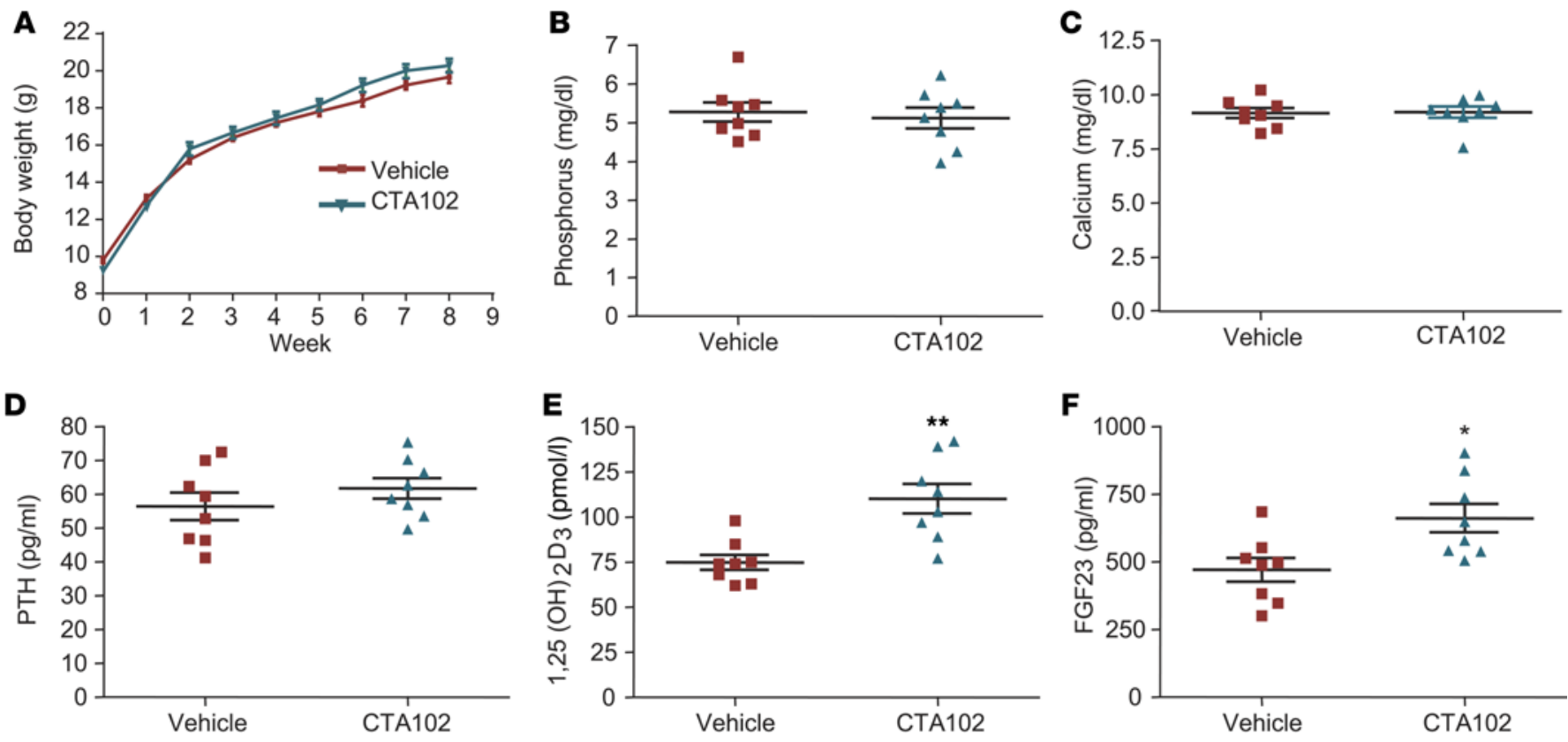

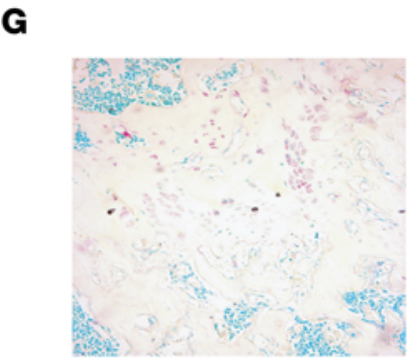

WT

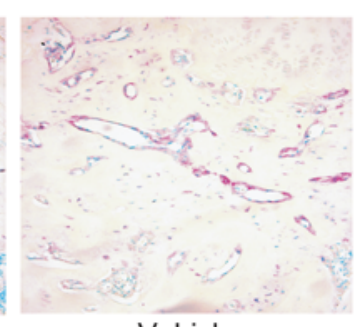

Vehicle

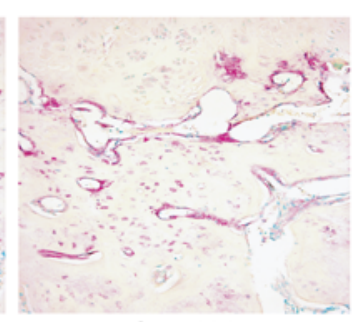

CTA102

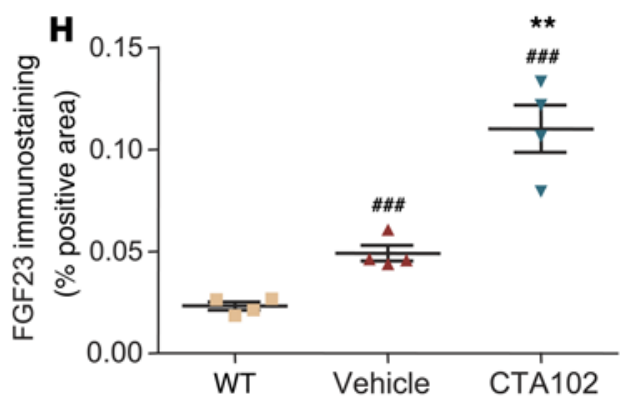

Figure 7. Body weight and serum biochemistry of vehicle- and CTA102-treated Hyp $Y$ mice. (A) Body weight and measurements for serum (B) phosphorus, (C) calcium, (D) PTH, (E) 1,25(OH) 2 , and (F) intact FGF23. For comparisons between the 2 groups, statistical analyses were performed using an unpaired, 2-tailed Student's $t$ test and are expressed as the mean \pm SEM $\left(n=8\right.$ mice/group). ${ }^{*} P<0.05$ and ${ }^{* *} P<0.01$, compared with vehicle-treated Hyp $Y$ mice. (C) FGF23 immunostaining shows methylene green-counterstained growth plate sections from WT and vehicle- and CTA102-treated Hyp $Y$ mice. Original magnification, $\times 400$. (H) Quantitative analysis of FGF23 immunostaining. Data represent the mean \pm SEM (4 animals/group). \#\#\# $P<0.001$ compared with WT mice; ${ }^{* *} P<0.01$ for CTA102-treated mice compared with vehicle. Statistics were calculated using an unpaired, 2-tailed Student's $t$ test.

potentially increasing FGF23 expression and secretion (62), this may not be the case. Treatment of XLH patients with phosphate and calcitriol is associated with concomitant increases in circulating FGF23 concentrations, but that may not necessarily diminish the therapeutic efficacy of these agents (63). The consequences of increasing FGF23 concentrations are not yet clear, because it is not known whether the degree of elevation in FGF23 levels correlates with disease severity in $X L H$ patients (63).

We now provide in vivo experimental evidence that pharmacological inhibition of CYP24 enzymatic activity profoundly influences the detrimental skeletal effects of the excess FGF23 activity that underlies FGF23 excess conditions such as Hyp and ectopic FGF23 expression. Remarkably, the observed improvements in skeletal abnormalities following CYP24 ablation or pharmacologic inhibition arose despite the persistence of hypophosphatemia. The implication is that the phosphaturic effect of FGF23 is not altered; rather, it is the inhibition of CYP24 activity in peripheral tissues such as parathyroid cells, osteoblasts, and chondrocytes that leads to the improved growth plate development and bone mineralization. Targeting CYP24 therefore provides the opportunity to increase endogenous levels of $1,25(\mathrm{OH})_{2} \mathrm{D}$ or reduce the effective dose of exogenous $1,25(\mathrm{OH})_{2} \mathrm{D}$. A theoretical advantage of using CYP24 inhibitors in combination with calcitriol is based on the overexpression of CYP24 within normal tissues. Therefore, inhibition of this enzyme would result in higher calcitriol levels in target cells such as chondrocytes and osteoblasts, thus enhancing their differentiation and function.

In conclusion, we report that introduction of the null Cyp24 allele into $H y p$ and FGF23-transgenic backgrounds prevents the development of the rachitic and osteomalacic bone phenotype by improving the histomorphometric parameters of bone health. We also provide evidence that this effect arises independently of the associated abnormalities in phosphorus handling, corroborating the supposition that it is the autocrine/paracrine effects of $1,25(\mathrm{OH})_{2} \mathrm{D}$ that mediate these beneficial effects within the skeletal microenvironment. 
A

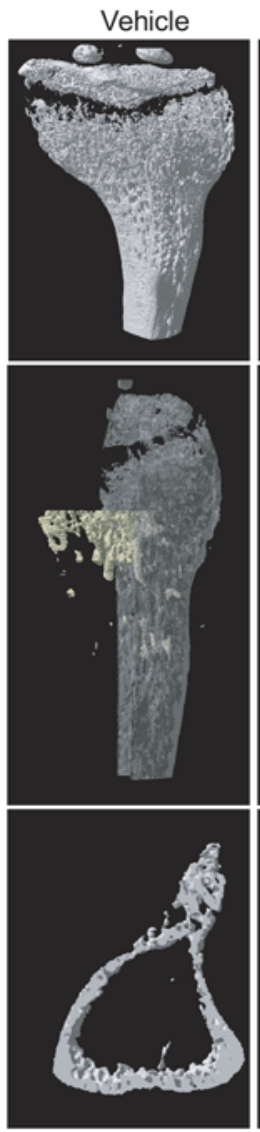

B
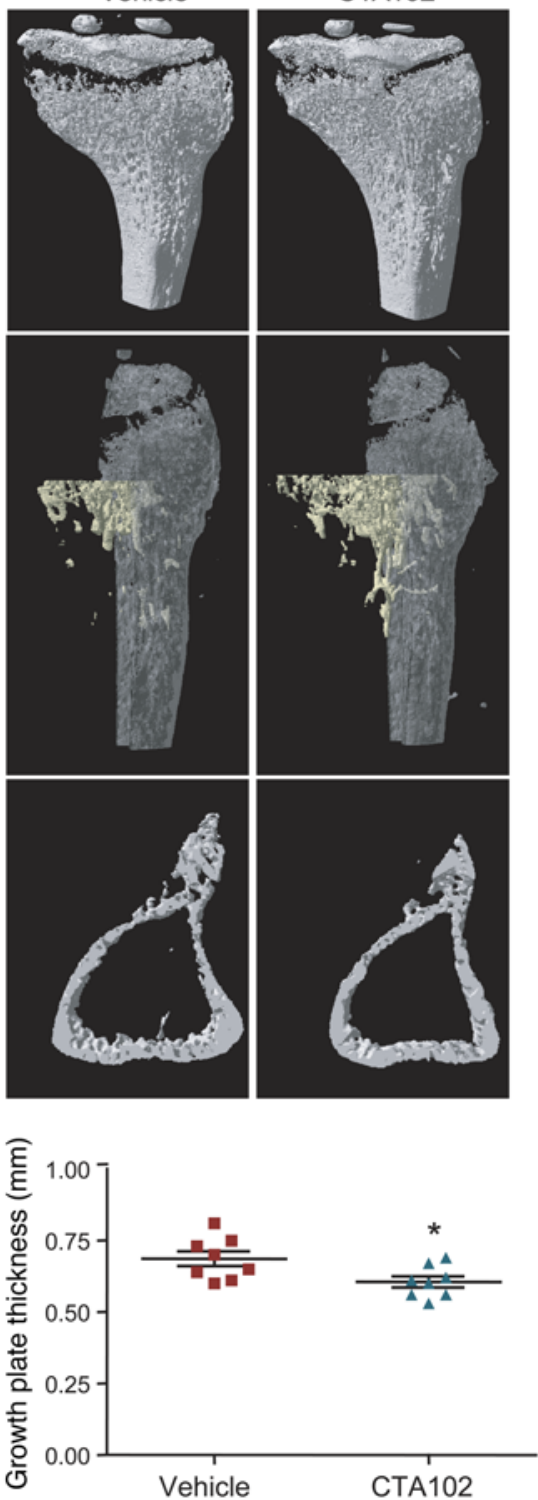

C

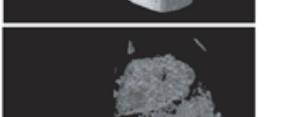

D

\section{F}

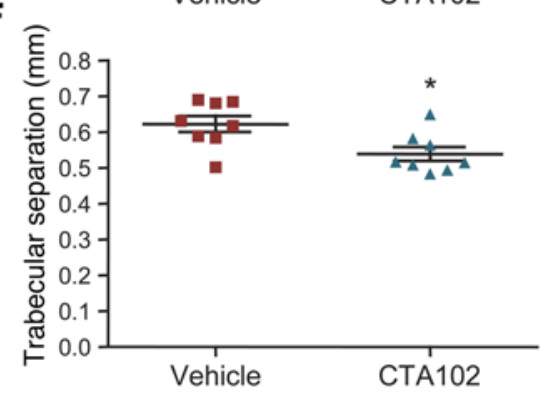

Figure 8. $\mu \mathrm{CT}$ and histomorphometric analysis of Hyp $Y$ long bones following treatment with CTA102. (A) Proximal tibiae 3D reconstruction from $\mu C T$ scans. Top panel: growth plate; middle panel: trabecular bone; bottom panel: cross section of cortex. (B) Quantitative histomorphometry for growth plate thickness, (C) osteoid volume (\%), (D) ratio of bone volume over total volume (BV/TV), (E) trabecular number, and (F) trabecular separation. Data represent the mean \pm SEM (8 animals/group). ${ }^{*} P<0.05$ and ${ }^{* *} P<0.01$ for CTA102-treated mice compared with vehicle. Data were calculated using an unpaired, 2-tailed Student's $t$ test.

hybridized to the radiolabeled DNA fragment at $42^{\circ} \mathrm{C}$ overnight. The membranes were washed and autoradiograms prepared using Kodak BioMax film at $-80^{\circ} \mathrm{C}$ with intensifying screens.

DNA fragments for the template DNA to identify $F^{T g}$ mice and mouse sex (sex-determined region on the Y chromosome [SRY]) were previously described (9). Exon 12 of Cyp24, corresponding to nucleotides 19573147 of the mouse gene (NCBI accession number D49438) was amplified by PCR using a pair of primers (forward: 5'-CCCTTCTGCAAGAAAACTGC-3'; reverse: 5'-GCCTGTGTCAGCCATACAAA-3'), subcloned, and sequenced, and this fragment was used as the template DNA to identify $C y p 24^{-/-}$mice.

To identify Hyp mice, oligonucleotide primers (forward: 5'-ATTGCTGACCATTTCCCTTG-3'; reverse: 5'-TGGAATCTTGGGGAAGTCAT-3') were used to amplify a 1,024-bp fragment. The PCR product was sequenced using an automated ABI 310 sequencer (Applied Biosystems, Thermo Fisher Scientific) for verifi-

\section{Methods}

Animals. Hyp and C57/BJ6 WT mice were purchased from The Jackson Laboratory, and Hyp mice were maintained on a C57/BJ6 background. FGF23-transgenic $\left(F^{T g}\right)$ mice and Cyp24-heterozygous mice (Cyp24+/-) were generated in our respective laboratories $(7,14)$. All mice were fed a commercial rodent diet (2018 Rodent Laboratory Chow; Harlan Laboratories) and drank tap water.

We crossed male Cyp24 $4^{+/-}$and female Cyp24 $4^{+/-}$Hyp mice to obtain male homozygotes on a Hyp background (Cyp24-/- Hyp Y) and male Cyp24 $4^{+-} F^{T g}$ and female Cyp24 $4^{+-}$mice to obtain male homozygotes carrying the FGF23 transgene (Cyp24-/- $\left.F^{T g}\right)$. Mice were sacrificed approximately 50 days postpartum. Sera and tissues were procured for analysis and comparison with WT, Cyp24-/, $F^{T g}$, and Hyp controls.

Mouse genotyping. Mice were screened by Southern blot analysis of tail-tip DNA prepared from a 1-cm portion of their tails. Briefly, $10 \mu \mathrm{g}$ genomic DNA was digested with BamHI (for the FGF23 transgene, Cyp24, and Phex) or EcoRI (for SRY), separated by 1\% agarose gel electrophoresis, transferred to nitrocellulose membranes, and cation and then used as a probe in Southern blot analyses of tail-tip genomic DNA digested with BamHI.

Northern blot analysis. cDNA fragments corresponding to nucleotides 535-1586 of mouse 25-hydroxyvitamin D 24-hydroxylase (Cyp24; accession number D49438) and to nucleotides 421-1471 of mouse 25 -hydroxyvitamin $\mathrm{D}_{3} 1 \alpha$-hydroxylase ( $1 \alpha$-hydroxylase) (Gene Expresquantitative PCR (qPCR) of mouse kidney total RNA, subcloned, and sequenced. DNA probes for CYP24, $1 \alpha$-hydroxylase, and GAPDH were prepared using a Random Primed DNA Labeling Kit (Roche Molecular Diagnostics) and $\left[\gamma^{-32} \mathrm{P}\right] \mathrm{dCTP}(800 \mathrm{Ci} / \mathrm{mmol}$; PerkinElmer Life Sciences). Total RNA was isolated from kidney with TriPure Isolation Reagent (Roche Life Science), and 20- $\mu$ g aliquots were fractionated by electrophoresis on a $1 \%$ formaldehyde agarose gel, transferred to nitrocellulose membranes by upward capillary transfer in $20 \times$ SSC overnight, and hybridized to the radiolabeled cDNA fragments ( $48 \%$ formamide, $10 \%$ dextran sulfate, $5 \times$ SSC, $1 \times$ Denhardt's solution and 100 $\mu \mathrm{g} / \mathrm{ml}$ salmon sperm DNA) at $42^{\circ} \mathrm{C}$ overnight. The membranes were sion Omnibus [GEO] accession number AB006034) were prepared by 


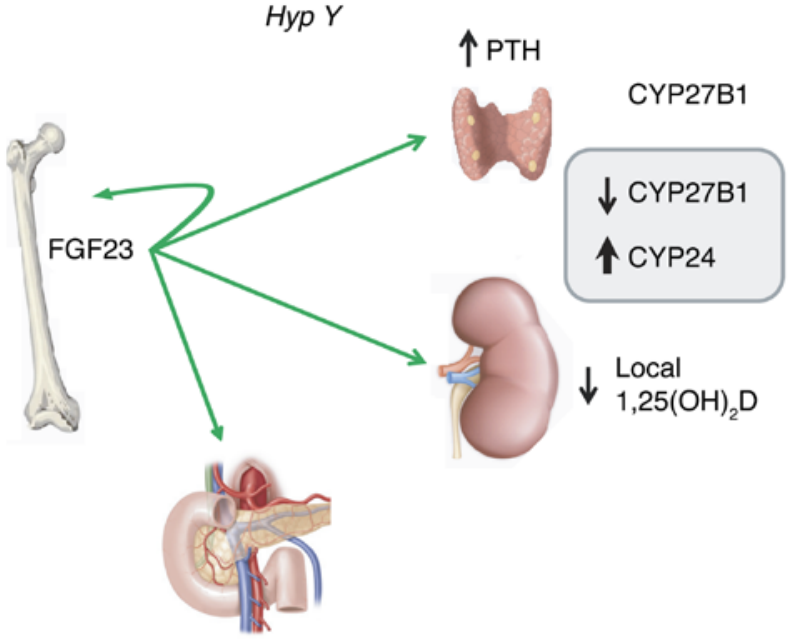

Impaired osteoblast/chondrocyte

differentiation and matrix mineralization

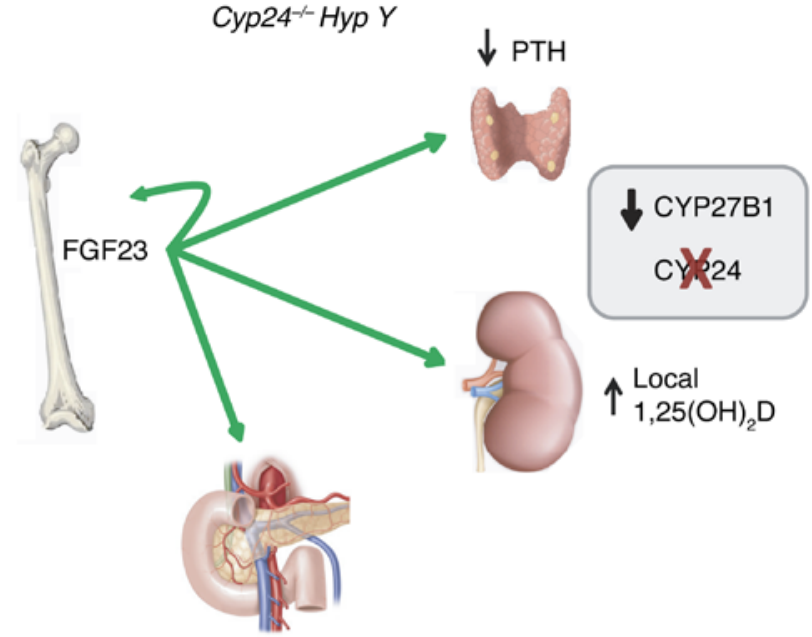

Improved osteoblast/chondrocyte differentiation and matrix mineralization

Figure 9. Schematic representation of CYP24 action and inactivation in Hyp Y mice. Left panel illustrates the role of CYP24 activity in Hyp Y mice. The preexisting FGF23 overactivity (green arrows) impairs CYP27B1 enzymatic action, while concurrently promoting that of CYP24 in renal and extrarenal tissues (bone, cartilage, parathyroid, kidney, duodenum), so that local tissue levels of $1,25(\mathrm{OH})_{2} \mathrm{D}$ decrease. This results in increased PTH secretion from the parathyroids and impairment of cellular differentiation and matrix mineralization at the bone and cartilage level. Cyp24 inactivation (right panel) increases cellular $1,25(\mathrm{OH})_{2} \mathrm{D}$ concentrations, thereby inhibiting PTH secretion and improving cellular differentiation and matrix mineralization at the bone and cartilage level, despite a further rise in circulating FGF23 levels. Hypocalcemia does not ensue, as rising local concentrations of 1,25(OH) $\mathrm{D}$ in the duodenum and kidneys promote expression of transport proteins critical for calcium absorption and reabsorption, respectively.

washed in $0.1 \%$ SDS plus $2 \times$ SSC for 15 minutes at room temperature with rotation and then in $0.1 \%$ SDS plus $0.1 \% \times$ SSC for another 15 minutes at $60^{\circ} \mathrm{C}$. The autoradiograms were prepared using Kodak BioMax film at $-80^{\circ} \mathrm{C}$ with intensifying screens. Quantification of signal intensity on autoradiograms was performed using ImageJ software (NIH).

Serum biochemistry. Serum concentrations of calcium, inorganic phosphorus, creatinine, and serum ALP were determined by routine methods following the manufacturer's instructions (Pointe Scientific Inc.). Serum-intact PTH was measured using an ELISA (Immutopics Inc.), whereas $1 \alpha, 25(\mathrm{OH})_{2} \mathrm{D}_{3}$ determinations were performed using a commercially available radioimmunoassay kit (Immunodiagnostic Systems Ltd.). Mouse serum levels of FGF23 were measured by an ELISA (KAINOS Laboratories Inc.). Serum osteocalcin and plasma FGF23 (C-terminal fragment) levels were measured using ELISA kits (Immutopics Inc.).

Skeletal radiographs. The femur was removed and dissected free of soft tissue, and radiographs were taken using a Faxitron Model 805 radiographic inspection system under constant conditions $(22 \mathrm{kV}$ voltage and a 4-minute exposure time) using Kodak X-Omat TL film.

$\mu C T$ analysis. Tibiae were removed and dissected free of soft tissue, fixed in PLP fixative (2\% paraformaldehyde containing $0.075 \mathrm{M}$ lysine and $0.01 \mathrm{M}$ sodium periodate solution) overnight at $4^{\circ} \mathrm{C}$, and analyzed by $\mu \mathrm{CT}$ using a SkyScan 1072 Scanner (Bruker) and the associated SkyScan analysis software, as described previously (64). Briefly, image acquisition was performed at $100 \mathrm{kV}$ and $98 \mathrm{~mA}$ with a $0.9^{\circ}$ rotation between frames. During scanning, the samples were enclosed in tightly fitted plastic wrap to prevent movement and dehydration. Threshold was applied to the images to segment the bone from the background. 2D images were used to generate 3D renderings with the 3D Creator software supplied with the instrument. The resolution of the $\mu \mathrm{CT}$ images is $18.2 \mu \mathrm{m}$.
Histology. Tissues were removed and fixed in PLP fixative overnight at $4^{\circ} \mathrm{C}$ and processed histologically as previously described (65). Briefly, the proximal end of the tibiae and the distal end of the femurs were decalcified in EDTA glycerol solution for 5 to 7 days at $4^{\circ} \mathrm{C}$. Decalcified femurs and tibiae and other tissues were dehydrated and embedded in paraffin, after which $5-\mu \mathrm{m}$ sections were cut on a rotary microtome. The sections were stained with $\mathrm{H} \& \mathrm{E}$ for tartrate-resistant acid phosphatase (TRAP) and with Picrosirius red for total collagen D expression. Undecalcified bones were embedded in LR White acrylic resin (London Resin Co. Ltd.). Sections of $1 \mu \mathrm{m}$ thickness were cut on an ultramicrotome and stained for ALP and mineral with the von Kossa staining procedure using toluidine blue as a counterstain.

Histochemicalstaining for ALP and TRAP. Enzyme histochemistry for ALP activity was performed as previously described (17). Briefly, following preincubation overnight in $1 \%$ magnesium chloride in 100 $\mathrm{mM}$ Tris-maleate buffer ( $\mathrm{pH}$ 9.2), dewaxed sections were incubated for 2 hours at room temperature in a 100-mM Tris-maleate buffer containing $0.2 \mathrm{mg} / \mathrm{ml}$ naphthol AS-MX phosphate (Sigma-Aldrich) dissolved in ethylene glycerol monomethyl ether (Sigma-Aldrich) as a substrate, and $0.4 \mathrm{mg} / \mathrm{ml}$ Fast Red TR (Sigma-Aldrich) as a stain for the reaction product. After being washed with distilled water, the sections were counterstained with VECTOR Methyl Green (Vector Laboratories) and mounted with Kaiser's glycerol gelatin.

Enzyme histochemistry for TRAP was performed as previously described (66). Dewaxed sections were preincubated for $20 \mathrm{~min}$ utes in buffer containing $50 \mathrm{mM}$ sodium acetate and $40 \mathrm{mM}$ sodium tartrate at $\mathrm{pH}$ 5.0. Sections were then incubated for 15 minutes at room temperature in the same buffer containing $2.5 \mathrm{mg} / \mathrm{ml} \mathrm{naph-}$ thol AS-MX phosphate in dimethylformamide as a substrate and 0.5 
$\mathrm{mg} / \mathrm{ml}$ Fast Garnet GBC (Sigma-Aldrich) as a color indicator for the reaction product. After washing with distilled water, the sections were counterstained with methyl green and mounted in Kaiser's glycerol gelatin.

IHC for FGF23 and CYP27B1. Sections were deparaffinized and hydrated through a series of baths from $100 \%$ to $30 \%$ ethanol, followed by washing under running water. Sections were digested with $0.05 \%$ hyaluronidase (Sigma-Aldrich) for 20 minutes and washed 3 times with Tris-buffered saline-Tween 20 (TBST) containing $20 \mathrm{mM}$ Tris, 0.15 M NaCl (pH 7.6), and 0.1\% (wt/vol) Tween-20. Tissue sections were blocked in TBST containing 0.5\% BSA and 10\% normal serum for 1 hour. Primary FGF23 Ab (R\&D Systems; MAB26291) and sheep anti-mouse CYP27B1 IgG fraction (The Binding Site Group Ltd.) were applied for 17 hours at room temperature in a humidified chamber. Sections were washed with Tris-buffered high-salt salineTween-20 (TBST-high $\mathrm{NaCl}$ ) containing $20 \mathrm{mM}$ Tris, $1.5 \mathrm{M} \mathrm{NaCl}$ (pH 7.6), and 0.1\% (wt/vol) Tween-20 for 10 minutes and washed twice in TBST each time for 5 minutes.

Biotin-conjugated secondary Abs were diluted (1:200) in TBST$0.05 \%$ BSA and applied to the sections for 1 hour at room temperature in a humidified chamber. Washings with sequential TBSThigh $\mathrm{NaCl}$ solution, followed by TBST, were performed to remove unbound Abs. ABC-AP solutions diluted in TBST were applied to the sections for 45 minutes at room temperature in a humidified chamber. After washing, positive signals were developed using a mixture of naphthol and phosphate and fast red dye in Tris-malate buffer $(\mathrm{pH} 9.5)$ in the presence of levamisole.

qPCR analysis. Total RNA was isolated from kidney and duodenum with TriPure Isolation Reagent (Roche Molecular Diagnostics). cDNA was synthesized using the Expand Reverse Transcriptase and Primer p(dT)15 (Roche Molecular Diagnostics). qPCR analysis was performed with the LightCycler FastStart DNA Master SYBR Green I Kit and LightCycler V2.0 (Roche Molecular Diagnostics). Results were normalized to actin levels. The primers used for qPCR were as follows: actin: forward, 5'-AAGGCCAACCGTGAAAAGAT-3' and reverse, 5'-GTGGTACGACCAGAGGCATAC-3'; calbindin D9K (S100g): forward, 5'-TCCTGCAGAAATGAAGAGCA-3' and reverse, 5'-GCTGGGGAACTCTGACTGAA-3'; calbindin D28K (Calb1): forward, 5'-CCACCTGCAGTCATCTCTGA-3' and reverse, 5'-TTCCGGTGATAGCTCCAATC-3'; Trpv5: forward, 5'-CACAG-
CAATGTTCAGCACCT-3' and reverse, 5'-GGCAAAGGTGGCATAGGTAA-3'; Trpv6: forward, 5'-GCACTGTTCAGCACCTTTGA-3' and reverse, 5'-GCAAAGGCAGCGTAGATAAC-3'.

Computer-assisted image analysis. After staining of sections from mice of each genotype, images of fields were photographed with a Sony digital camera. Imagines of micrographs from single sections were digitally recorded using a rectangular template, and recordings were processed and analyzed using Northern Eclipse image analysis software as previously described (64).

CYP24 inhibitor. The CYP24 inhibitor CTA102 was provided by Cytochroma Inc. (now OPKO Health Inc.). Twenty-five-day-old male Hyp mice were injected i.p. daily with either $100 \mu$ vehicle (saline/ propylene-glycol at a ratio of $45 \%: 55 \%$ ) or vehicle containing CTA102 $(25 \mu \mathrm{g} / \mathrm{kg} /$ day $)$ for 8 weeks. Mice were sacrificed, and sera and tissues were procured for analysis.

Statistics. Statistical comparisons for all genotypes were made using 1-way ANOVA with Tukey's multiple comparisons post test with Prism software, version 4 (GraphPad Software). For comparisons between 2 groups, statistical analysis was performed using an unpaired, 2-tailed Student's $t$ test. All data are presented as the mean \pm SEM. A $P$ value of less than 0.05 was considered significant.

Study approval. All animal experiments were reviewed and approved by the IACUC of McGill University.

\section{Author contributions}

$\mathrm{XB}, \mathrm{DM}, \mathrm{SX}$, and DQ conducted all the experiments and acquired the data. RSA provided the Cyp24-null mice and revised the manuscript. MP provided the CYP24 inhibitor CTA102, designed part of the research studies, and revised the manuscript. XB, AG, DG, and ACK designed the research studies, analyzed the data, and wrote the manuscript.

\section{Acknowledgments}

This work was supported by the Kidney Foundation of Canada (KFOC100012, to A.C. Karaplis and X. Bai) and Canadian Institutes of Health Research grants (to D. Goltzman and R. St-Arnaud).

Address correspondence to: Andrew C. Karaplis, Lady Davis Institute for Medical Research, Division of Endocrinology, Jewish General Hospital, 3755 Cote Ste Catherine, Montreal, Quebec, H3T 1E2 Canada. Phone: 514.340.7550; E-mail: akarapli@jgh.mcgill.ca.
1. Bergwitz C, Juppner H. FGF23 and syndromes of abnormal renal phosphate handling. Adv Exp Med Biol. 2012;728:41-64.

2. Shimada T, et al. Cloning and characterization of FGF23 as a causative factor of tumorinduced osteomalacia. Proc Natl Acad Sci US A. 2001;98(11):6500-6505.

3. Quarles LD. Role of FGF23 in vitamin D and phosphate metabolism: implications in chronic kidney disease. Exp Cell Res. 2012;318(9):1040-1048.

4. Saito H, et al. Human fibroblast growth factor-23 mutants suppress $\mathrm{Na}^{+}$-dependent phosphate co-transport activity and $1 \alpha, 25-$ dihydroxyvitamin D3 production. J Biol Chem. 2003;278(4):2206-2211.

5. Bai XY, Miao D, Goltzman D, Karaplis AC. The autosomal dominant hypophosphatemic rickets $\mathrm{R} 176 \mathrm{Q}$ mutation in fibroblast growth factor 23 resists proteolytic cleavage and enhances in vivo biological potency. J Biol Chem. 2003;278(11):9843-9849.

6. Ben-Dov IZ, et al. The parathyroid is a target organ for FGF23 in rats. JClin Invest. 2007;117(12):4003-4008.

7. Bai X, Miao D, Li J, Goltzman D, Karaplis AC. Transgenic mice overexpressing human fibroblast growth factor 23 (R176Q) delineate a putative role for parathyroid hormone in renal phosphate wasting disorders. Endocrinology. 2004;145(11):5269-5279.

8. Roy S, Martel J, Ma S, Tenenhouse HS. Increased renal 25-hydroxyvitamin D3-24hydroxylase messenger ribonucleic acid and immunoreactive protein in phosphatedeprived Hyp mice: a mechanism for accelerated 1,25-dihydroxyvitamin D3 catabolism in X-linked hypophosphatemic rickets. Endocrinology. 1994;134(4):1761-1767.

9. Bai X, Miao D, Goltzman D, Karaplis AC. Early lethality in Hyp mice with targeted deletion of Pth gene. Endocrinology. 2007;148(10):4974-4983.

10. [No authors listed]. A gene (PEX) with homologies to endopeptidases is mutated in patients with X-linked hypophosphatemic rickets. Nat Genet. 1995;11(2):130-136.

11. Beck L, et al. Pex/PEX tissue distribution and evidence for a deletion in the 3 ' region of the Pex gene in X-linked hypophosphatemic mice. JClin Invest. 1997;99(6):1200-1209.

12. Beck L, Karaplis AC, Amizuka N, Hewson AS, Ozawa H, Tenenhouse HS. Targeted inactivation of Npt 2 in mice leads to severe renal phosphate wasting, hypercalciuria, and skeletal abnormalities. Proc Natl Acad Sci U S A. 
1998;95(9):5372-5377.

13. Prie D, et al. Nephrolithiasis and osteoporosis associated with hypophosphatemia caused by mutations in the type 2a sodium-phosphate cotransporter. NEngl JMed. 2002;347(13):983-991.

14. St-Arnaud R, et al. Deficient mineralization of intramembranous bone in vitamin D-24hydroxylase-ablated mice is due to elevated 1,25-dihydroxyvitamin $\mathrm{D}$ and not to the absence of 24,25-dihydroxyvitamin D. Endocrinology. 2000;141(7):2658-2666.

15. Fujiwara I, Aravindan R, Horst RL, Drezner MK. Abnormal regulation of renal 25-hydroxyvitamin $\mathrm{D}-1 \alpha$-hydroxylase activity in X-linked hypophosphatemia: a translational or post-translational defect. J Bone Miner Res. 2003;18(3):434-442.

16. White KE, Carn G, Lorenz-Depiereux B, Benet-Pages A, Strom TM, Econs MJ. Autosomal-dominant hypophosphatemic rickets (ADHR) mutations stabilize FGF-23. Kidney Int. 2001;60(6):2079-2086.

17. Miao D, Scutt A. Histochemical localization of alkaline phosphatase activity in decalcified bone and cartilage. J Histochem Cytochem. 2002;50(3):333-340.

18. Andrukhova O, et al. FGF23 promotes renal calcium reabsorption through the TRPV5 channel. EMBO J. 2014;33(3):229-246.

19. Jeon US. Kidney and calcium homeostasis. Electrolyte Blood Press. 2008;6(2):68-76.

20. Wasserman RH, Fullmer CS. Vitamin D and intestinal calcium transport: facts, speculations and hypotheses. J Nutr. 1995;125(7 suppl):1971S-1979S.

21. Balesaria S, Sangha S, Walters JR. Human duodenum responses to vitamin D metabolites of TRPV6 and other genes involved in calcium absorption. Am J Physiol Gastrointest Liver Physiol. 2009;297(6):G1193-G1197.

22. Colnot $\mathrm{S}$, et al. Transgenic analysis of the response of the rat calbindin-D 9k gene to vitamin D. Endocrinology. 2000;141(7):2301-2308.

23. Boyan BD, Sylvia VL, Dean DD, Del Toro F, Schwartz Z. Differential regulation of growth plate chondrocytes by $1 \alpha, 25-(\mathrm{OH}) 2 \mathrm{D} 3$ and 24R,25-(OH)2D3 involves cell-maturationspecific membrane-receptor-activated phospholipid metabolism. Crit Rev Oral Biol Med. 2002;13(2):143-154.

24. Tomon M, Tenenhouse HS, Jones G. Expression of 25-hydroxyvitamin D3-24-hydroxylase activity in Caco-2 cells. Endocrinology. 1990;126(6):2868-2875.

25. DeLuca HF. Overview of general physiologic features and functions of vitamin D. Am J Clin Nutr. 2004;80(6 suppl):1689S-1696S.

26. Tenenhouse HS, Yip A, Jones G. Increased renal catabolism of 1,25-dihydroxyvitamin D3 in murine X-linked hypophosphatemic rickets. JClin Invest. 1988;81(2):461-465.

27. Kumar R, Thompson JR. The regulation of parathyroid hormone secretion and synthesis. JAm Soc Nephrol. 2011;22(2):216-224.

28. Azam N, Zhang MY, Wang X, Tenenhouse HS, Portale AA. Disordered regulation of renal 25-hydroxyvitamin D-1alpha-hydroxylase gene expression by phosphorus in X-linked hypophosphatemic (hyp) mice. Endocrinology. 2003;144(8):3463-3468.
29. Tashiro K, Abe T, Oue N, Yasui W, Ryoji M. Characterization of vitamin D-mediated induction of the CYP 24 transcription. Mol Cell Endocrinol. 2004;226(1-2):27-32.

30. Chen KS, DeLuca HF. Cloning of the human 1 alpha,25-dihydroxyvitamin D-3 24-hydroxylase gene promoter and identification of two vitamin D-responsive elements. Biochim Biophys Acta. 1995;1263(1):1-9.

31. Meir T, et al. Deletion of the vitamin D receptor specifically in the parathyroid demonstrates a limited role for the receptor in parathyroid physiology. Am J Physiol Renal Physiol. 2009;297(5):F1192-F1198.

32. Anderson PH, Atkins GJ, Turner AG, Kogawa M, Findlay DM, Morris HA. Vitamin D metabolism within bone cells: effects on bone structure and strength. Mol Cell Endocrinol. 2011;347(1-2):42-47.

33. van Driel M, et al. Evidence for auto/paracrine actions of vitamin $\mathrm{D}$ in bone: $1 \alpha$-hydroxylase expression and activity in human bone cells. FASEB J. 2006;20(13):2417-2419.

34. Geng S, Zhou S, Glowacki J. Effects of 25-hydroxyvitamin $\mathrm{D}(3)$ on proliferation and osteoblast differentiation of human marrow stromal cells require CYP27B1/1 $\alpha$-hydroxylase. J Bone Miner Res. 2011;26(5):1145-1153.

35. Siu-Caldera ML, Zou L, Ehrlich MG Schwartz ER, Ishizuka S, Reddy GS. Human osteoblasts in culture metabolize both 1 alpha, 25-dihydroxyvitamin D3 and its precursor 25-hydroxyvitamin D3 into their respective lactones. Endocrinology. 1995;136(10):4195-4203.

36. Howard GA, Turner RT, Sherrard DJ, Baylink DJ. Human bone cells in culture metabolize 25-hydroxyvitamin D3 to 1,25-dihydroxyvitamin D3 and 24,25-dihydroxyvitamin D3. J Biol Chem. 1981;256(15):7738-7740.

37. Gardiner EM, et al. Increased formation and decreased resorption of bone in mice with elevated vitamin D receptor in mature cells of the osteoblastic lineage. FASEB J. 2000;14(13):1908-1916.

38. Anderson $\mathrm{PH}$, et al. The pleiotropic effects of vitamin D in bone. J Steroid Biochem Mol Biol. 2013;136:190-194.

39. Anderson PH, O'Loughlin PD, May BK, Morris HA. Modulation of CYP27B1 and CYP24 mRNA expression in bone is independent of circulating 1,25(OH)2D3 levels. Bone. 2005;36(4):654-662.

40. Horwood NJ, Elliott J, Martin TJ, Gillespie MT. Osteotropic agents regulate the expression of osteoclast differentiation factor and osteoprotegerin in osteoblastic stromal cells. Endocrinology. 1998;139(11):4743-4746.

41. Wang Y, Zhu J, DeLuca HF. Identification of the vitamin D receptor in osteoblasts and chondrocytes but not osteoclasts in mouse bone. J Bone Miner Res. 2014;29(3):685-692.

42. Dardenne O, Prud'homme J, Hacking SA, Glorieux FH, St-Arnaud R. Correction of the abnormal mineral ion homeostasis with a highcalcium, high-phosphorus, high-lactose diet rescues the PDDR phenotype of mice deficient for the 25-hydroxyvitamin D-1 $\alpha$-hydroxylase (CYP27B1). Bone. 2003;32(4):332-340.

43. Naja RP, Dardenne O, Arabian A, St Arnaud R. Chondrocyte-specific modulation of Cyp27b1 expression supports a role for local synthesis of 1,25-dihydroxyvitamin D3 in growth plate development. Endocrinology. 2009;150(9):4024-4032.

44. Masuyama R, et al. Vitamin D receptor in chondrocytes promotes osteoclastogenesis and regulates FGF23 production in osteoblasts. JClin Invest. 2006;116(12):3150-3159.

45. Bai X, et al. Partial rescue of the Hyp phenotype by osteoblast-targeted PHEX (phosphateregulating gene with homologies to endopeptidases on the $\mathrm{X}$ chromosome) expression. Mol Endocrinol. 2002;16(12):2913-2925.

46. Liu S, Guo R, Tu Q, Quarles LD. Overexpression of Phex in osteoblasts fails to rescue the Hyp mouse phenotype. J Biol Chem. 2002;277(5):3686-3697.

47. Erben RG, Mayer D, Weber K, Jonsson K, Juppner H, Lanske B. Overexpression of human PHEX under the human beta-actin promoter does not fully rescue the Hyp mouse phenotype. JBone Miner Res. 2005;20(7):1149-1160.

48. Boskey A, et al. The PHEX transgene corrects mineralization defects in 9-month-old hypophosphatemic mice. Calcif Tissue Int. 2009;84(2):126-137.

49. Labrie F, et al. Intracrinology: role of the family of 17 beta-hydroxysteroid dehydrogenases in human physiology and disease. J Mol Endocrinol. 2000;25(1):1-16.

50. Schuessler M, Astecker N, Herzig G, Vorisek $\mathrm{G}$, Schuster I. Skin is an autonomous organ in synthesis, two-step activation and degradation of vitamin D(3): CYP27 in epidermis completes the set of essential vitamin $\mathrm{D}(3)$-hydroxylases. Steroids. 2001;66(3):399-408.

51. Muindi JR, et al. CYP24A1 inhibition enhances the antitumor activity of calcitriol. Endocrinology. 2010;151(9):4301-4312.

52. Luo W, Yu WD, Ma Y, Chernov M, Trump DL, Johnson CS. Inhibition of protein kinase CK2 reduces Cyp24a1 expression and enhances 1,25-dihydroxyvitamin $\mathrm{D}(3)$ antitumor activity in human prostate cancer cells. Cancer Res. 2013;73(7):2289-2297.

53. Liu S, et al. Fibroblast growth factor 23 is a counter-regulatory phosphaturic hormone for vitamin D. JAm Soc Nephrol. 2006; 17(5):1305-1315.

54. Jonsson KB, et al. Fibroblast growth factor 23 in oncogenic osteomalacia and X-linked hypophosphatemia. NEngl JMed.2003; 348(17):1656-1663.

55. Harrell RM, Lyles KW, Harrelson JM, Friedman NE, Drezner MK. Healing of bone disease in $\mathrm{X}$-linked hypophosphatemic rickets/osteomalacia. JClin Invest. 1985;75(6):1858-1868.

56. Verge CF, Lam A, Simpson JM, Cowell CT, Howard NJ, Silink M. Effects of therapy in $\mathrm{X}$-linked hypophosphatemic rickets. N Engl JMed. 1991;325(26):1843-1848.

57. Marie PJ, Glorieux FH. Relation between hypomineralized periosteocytic lesions and bone mineralization in vitamin D-resistant rickets. Calcif Tissue Int. 1983;35(4-5):443-448.

58. Stickler GB, Morgenstern BZ. Hypophosphataemic rickets: final height and clinical symptoms in adults. Lancet . 1989;2(8668):902-905.

59. Wohrle S, et al. Pharmacological inhibition of fibroblast growth factor (FGF) receptor signaling 


\section{RESEARCH ARTICLE}

ameliorates FGF23-mediated hypophosphatemic rickets. J Bone Miner Res. 2013;28(4):899-911.

60. Zhang MY, Ranch D, Pereira RC, Armbrecht HJ, Portale AA, Perwad F. Chronic inhibition of ERK1/2 signaling improves disordered bone and mineral metabolism in hypophosphatemic (Hyp) mice. Endocrinology. 2012;153(4):1806-1816.

61. Carpenter TO, et al. Randomized trial of the antiFGF23 antibody KRN23 in X-linked hypophosphatemia. JClin Invest. 2014;124(4):1587-1597.

62. Saito H, et al. Circulating FGF-23 is regulated by 1alpha,25-dihydroxyvitamin D3 and phosphorus in vivo. J Biol Chem. 2005;280(4):2543-2549.

63. Imel EA, DiMeglio LA, Hui SL, Carpenter TO, Econs MJ. Treatment of X-linked hypophosphatemia with calcitriol and phosphate increases circulating fibroblast growth factor 23 concentrations. J Clin Endocrinol Metab. 2010;95(4):1846-1850.

64. Miao D, Li J, Xue Y, Su H, Karaplis AC, Goltzman D. Parathyroid hormone-related peptide is required for increased trabecular bone volume in parathyroid hormone-null mice. Endocrinology.
The Journal of Clinical Investigation

2004;145(8):3554-3562.

65. Miao D, Bai X, Panda D, McKee M, Karaplis A, Goltzman D. Osteomalacia in hyp mice is associated with abnormal phex expression and with altered bone matrix protein expression and deposition. Endocrinology. 2001;142(2):926-939.

66. Miao D, Scutt A. Recruitment, augmentation and apoptosis of rat osteoclasts in 1,25-

(OH)2D3 response to short-term treatment with 1,25-dihydroxyvitamin D3 in vivo. BMC Musculoskelet Disord. 2002;3:16. 